\title{
Punzones y varillas metálicas en la Prehistoria reciente española: un estudio tecnológico ${ }^{1}$
}

\author{
Salvador Rovira Lloréns ${ }^{2}$ \\ Pablo Gómez Ramos ${ }^{3}$
}

\section{INTRODUCCIÓN}

El conocimiento y práctica de la metalurgia, primero del cobre y posteriormente del bronce, posibilitó la fabricación de los primeros punzones que coexistirán con otros realizados en materias primas diversas, principalmente de hueso. El reducido repertorio formal de objetos de uso cotidiano del Neolítico y Calcolítico motivó que las primeras experimentaciones en metal se destinasen a la producción de tipos de objetos ya conocidos con anterioridad, como por ejemplo punzones, puntas de flecha y hachas.

Ya en 1987 uno de nosotros (S. R.) fijó la atención, por su abundancia y continuidad en el registro arqueológico, en los punzones metálicos. Desde entonces hasta hoy el estudio se ha visto incrementado enormemente con una serie total superior a las 400 piezas y que abarca un arco cronológico desde el Calcolítico hasta finales de la Edad del Hierro. Tan amplio abanico permite llegar a conclusiones más asentadas, y sobre todo, más contrastadas que las presentadas entonces en el terreno de la tecnología metalúrgica, y nos ayuda a perfilar algunos interesantes aspectos arqueológicos que no se habian señalado hasta la fecha.

No pretendemos, sin embargo, detallar de manera pormenorizada el contexto arqueológico de cada hallazgo. Nos mueve a ello varias razones:

1 El presente estudio es resultado parcial del desarrollo del proyecto de investigación "Arqueometalurgia de la P. Ibérica: Tecnologia y cambio cultural durante la Edad del Bronce", CICYT PB92-0315.

Museo de América, Madrid.

3 Universidad Autónoma de Madrid. Becario de FPI. 
muchas de las piezas están aún inéditas, sería una tarea que ocuparía mucho más espacio del que podemos dedicar a estas páginas $y$, lo que creemos más importante, no aportaría datos significativos al tema principal de este artículo, es decir, al proceso tecnológico y la evolución del trabajo artesano-metalúrgico durante la Pre y Protohistoria peninsular.

\section{ESTUDIO ARQUEOMETALÚRGICO}

La documentación analítica existente es cuantitativa y cualitativamente muy desigual para las diversas regiones naturales que configuran la fracción española de la Península Ibérica. Así, mientras que para el Sureste (especialmente Almería), La Mancha y la Cuenca del Duero se ha podido reunir un volumen de análisis importante, el resto de las regiones no son tan afortunadas, ofreciendo muchas de ellas carencias difíciles de salvar en alguna o varias de las etapas en las que solemos dividir el devenir histórico. El estado actual de la investigación prehistórica y las dificultades para acceder a los materiales de interés para este estudio también influyen negativamente.

Otro problema que hay que afrontar cuando se trata de ofrecer una perspectiva geográfico-cultural surge de la dificultad de trabar en un entramado unitario las secuencias culturales del mosaico peninsular. La adecuación al modelo sencillo de unas sociedades metalúrgicas articuladas desde el Calcolítico a la Edad del Hierro encuentra no pocas dificultades en las fases más antiguas (Calcolítico, Bronce Antiguo, Bronce Medio) de algunas áreas.

En el Sureste (Andalucía oriental y Murcia) se registran las fechas más tempranas de poblados con actividad metalúrgica. La Fase II de Almizaraque ha proporcionado dataciones entre el 2562-2468 cal. a.C. (CAStaño et al. 1991: 50); El Malagón, 2300-1900 a.C. (ARRIBAs et al. 1989: 74), y Terrera Ventura, 2100-1950 a.C. (GusI y OLARIA 1991: 280), etc. Desde el punto de vista de la periodización, el Calcolítico arranca aqui a mediados del III milenio y finaliza hacia el 1990 a.C., momento en que comienza la fase más antigua de la Cultura de El Argar inaugurando la Edad del Bronce. El Argar ocupa en el Sureste los periodos correspondientes al Bronce Antiguo (tradicionalmente Argar A) y Medio o Pleno (Argar B) de otras regiones, durando grosso modo desde 1900 a 1400 a.C. Seguiria una etapa de Bronce Tardio (Argar C) hasta el siglo XI aproximadamente para, a continuación, entrar en el Bronce Final (SCHUBART y ARTEAGA 1986). El Bronce Final plantea aquí no pocos interrogantes en su tramo anterior al siglo IX a.C., a pesar de la sistematización propuesta por Molina (1978). Los contextos arqueológicos son todavía más bien 
Punzones y varillas metálicas en la Prehistoria reciente española...

escasos (véase la revisión hecha recientemente por MARTín DE LA CRUZ 1991: 59-60), y parecen sugerir un impase y nueva arrancada tras la crisis del mundo argárico, desde un substrato indígena al que llegaron creativos influjos exteriores (MOLINA 1978; ARTEAGA 1981).

En la cuenca alta del Guadalquivir se ha querido ver una larga etapa calcolitica que se iniciaria también a mediados del III milenio y llegaría hasta el 1600/1500 a.C., con cerámicas campaniformes de desarrollo tardío en sus últimos compases (CARRAsco et al 1980), aconteciendo luego una paulatina aunque peculiar aculturación argárica (MARTIN DE LA CRUZ 1991: 63 y 65) que enmarcaria el Bronce Pleno. En el Bajo Guadalquivir hay fechas para el Calcolítico Pleno hacia el 2500 a.C. (en Papa Uvas y otros yacimientos), pero el Calcolítico final aparece desdibujado (MARTín DE LA CRUz, 1991: 65), así como el desarrollo cultural durante gran parte del II milenio, a pesar de los sagaces intentos de Escacena y Frutos (1985), Pellicer (1986) y Caro (1988-89 y 1989) por identificar Bronce Antiguo y Pleno y redondear así un modelo de aplicación clásico.

La periodización unitaria de la Submeseta Sur, región ocupada por Castilla-La Mancha y la Comunidad de Madrid, es también complicada. Si, por un lado, yacimientos como la Cueva de Juan Barbero (Tielmes), La Esgaravita (Alcalá de Henares) y El Ventorro (Villaverde) han propiciado que se hablara de un periodo Calcolítico durante el cual se iniciaría la metalurgia del cobre, no es menos cierto que la carencia de buenas estratigrafías hace dificil encontrar una delimitación clara para el Campaniforme y, por ende, para el Bronce Antiguo. Las fechas radio carbónicas obtenidas en la fase precampaniforme de El Ventorro van del 2340 al 1930 a.C. (PRIEgo y Quero 1992: 368), resultando la última una aceptable fecha post quem para dicho Bronce Antiguo, que correría parejo a la cerámica Ciempozuelos.

No queda nada claro el comienzo del Bronce Medio o Pleno en la comunidad madrileña. Ni la pretendida contemporaneidad de cerámica campaniforme de tipo Ciempozuelos con otras especies más evolucionadas (Argar B) en la Fábrica de Euskalduna (ALMAGRo BASCH 1960) y El Tejar del Sastre (QUERo 1982) cuenta con buenos avales estratigráficos ni, aunque aceptáramos los argumentos, nos conducirian a fechas concretas (BLASCO et al. 1988-89). Tampoco sirve de mucho a efectos de cronologia absoluta el hallazgo de un asentamiento del horizonte Protocogotas I en el Caserio de Perales (Getafe), pues no hay todavía dataciones radiocarbónicas. Indica, eso si, que en el Bronce Medio local hay que incluir la secuencia Protocogotas I. El paralelismo parece claro con lo que acontece en la Submeseta Norte en yacimientos como Cogeces, Los Tolmos y Arevalillo, donde se ha definido un Bronce MedioProtocogotas con cerámicas incisas y boquique que llenaría el hueco 
entre Ciempozuelos y Cogotas I, entre los siglos xV y XIII a.C. (FERNÁNDEZPosse y MARTín 1991: 81). Pero su posición temporal respecto del complejo cultural representado por El Tejar del Sastre no está claramente definida, aunque con buena lógica se ha sugerido cierta sincronia parcial basada en la semejanza contextual de cerámicas lisas carenadas (BLAsco y Rovira 1992-93: 401). En Guadalajara, La Loma del Lomo (Cogolludo) presenta unos materiales característicos del Bronce Pleno fechados entre 1670 y 1420 a.C. (Valiente 1993), y podría servir de referencia (en tanto no se obtengan mayores precisiones) para la misma fase del Valle del Manzanares.

Más al sur, las tierras manchegas ordenan el registro arqueológico de su secuencia metalúrgica en el llamado Bronce de la Mancha, denominación que etiqueta todo el desarrollo cultural acaecido desde el 2250 al 1500 cal. a.C. (MARTín et al. 1993: 25), con enormes dificultades para diferenciar fases dada la monotonía tipológica de los materiales (MARTín et al. 1993: 30-31).

En el Levante, tras un Calcolítico sin apenas metalurgia, el Horizonte Campaniforme conducirá a un Bronce Valenciano con ciertos rasgos compartidos con el manchego y el argárico en su primer tramo. Pero, a diferencia del primero, el Bronce Valenciano se está estructurando según la secuencia del modelo clásico en las excavaciones de los últimos años (Gil-Mascarell 1981; Hernández y López 1992: 11).

A la vista de todas estas dificultades, una ordenación cronológica rigurosa tropezará con obstáculos insalvables. Por ello hemos preferido simplificar la seriación en dos sentidos: 1) eliminando del cómputo las piezas con cronología dudosa, y 2) agrupando ciertos conjuntos como el argárico del Sureste ${ }^{4} \mathrm{o}$ el Bronce de La Mancha ${ }^{5}$, y asi hacerlos comparables con otros conjuntos regionales encuadrados en el Bronce Antiguo o Medio.

4 La mayoria de los materiales aquí recogidos proceden de las antiguas excavaciones de Luis Siret, y actualmente es imposible distribuirlos dentro de la secuencia argárica que proponen trabajos modernos como los de Fuente Álamo. Como ya dedujera Lull (1983: 217), la morfometría del punzón no parece contener atributos de cronología. Como, por otro lado, la monotonia tecnológica tiñe toda la metalurgia argárica (MONTERo 1992: 196; 1993: 55), la diferenciación temporal entre los punzones argáricos resultaria irrelevante. A efectos de establecer comparaciones de indole tecnológica, los punzones argáricos podrán ser comparados con materiales del Bronce Antiguo y/o Medio sin que el valor estadistico de la prueba se resienta significativamente.

5 En este caso, los materiales de las motillas, morras y castillejos manchegos estarian en situación similar al Argar del Sureste, como indican Martin et al. (1993: 25), con fechas comprendidas entre 2250 y 1500 cal. a.C. 
Punzones y varillas metálicas en la Prehistoria reciente española...

\subsection{Los punzones calcoliticos}

Del Sureste se han analizado noventa y tres punzones pertenecientes a distintos yacimientos calcolíticos, principalmente Almizaraque, Los Millares, el Cerro de la Virgen y Las Angosturas (MONTERo 1992). La tipología es variada en cuanto a formas y tamaños: los hay biapuntados y de un solo extremo aguzado (algún ejemplar conserva restos evidentes de haber estado enmangado), predominando las secciones cuadrangulares sobre las circulares.

El metal de la composición es en todos los casos cobre con impurezas de arsénico y otros menores constituyentes y trazas. Aproximadamente la mitad de los punzones contienen menos del $1 \%$ As, por lo que no entrarian a formar parte de los llamados "cobres o bronces arsenicales" (esta categoría se otorga a las aleaciones con más del $1 \%$ As). El valor medio del arsénico es 1,94\%, con una desviación típica de 2,42 que indica una fuerte dispersión de los valores respecto de la media. Efectivamente, junto a las muchas piezas poco arsenicadas encontramos algunas otras con altas cargas de arsénico que se aproximan o superan el $10 \%$ en peso, todas ellas procedentes de Almizaraque.

Del Valle del Guadalquivir sólo hay un punzón analizado, de la Cueva del Higueral (Jerez), de cronologia dudosa dentro de la fase antigua de la Edad de los Metales, pero cuyo contexto sugiere una adscripción calcolítica. Es de cobre casi puro $(99,8 \%)$.

Tres punzones procedentes del término de Alange suministran toda la información disponible del Calcolítico extremeño. Son de cobre ligeramente arsenicado (entre 0,3 y $0,5 \%$ As).

Otros tres punzones de este periodo son de la región de Madrid, uno procedente de la Cueva de Juan Barbero (RoviRA y SANz 1984: 96) y dos recientemente analizados de La Esgaravita. Son piezas de cobre con una tasa de arsénico que oscila entre 0,0 y $0,9 \%$.

Los punzones calcolíticos de la Cuenca del Duero son en general pobres en arsénico. Hemos analizado ocho ejemplares, predominando los de tipo biapuntado. La mayoría procede de yacimientos abulenses en curso de excavación (Cantera de Halagas, La Teta, Los Itueros). EI porcentaje de arsénico oscila entre 0,0 y $0,6 \%$.

Quedan, finalmente, dos punzones gallegos extraídos durante las recientes excavaciones en Guidoiro Areoso (Vilanova de Arousa). Son piezas extraordinariamente interesantes pues se trata de bronces mixtos cobre-estaño-arsénico, los únicos conocidos por el momento de cronología tan antigua, y que podrían servir de apoyo a las hipótesis sobre 
tempranas relaciones maritimas de las costas de Galicia con el mundo metalúrgico de las Islas Británicas, ya propuestas entre otros por Harrison (1974), donde los objetos metálicos de bronce comenzaron a ser frecuentes a finales del III milenio (NEEDHAM et al 1989).

Mediante el análisis metalográfico se ha determinado la técnica de elaboración de estos instrumentos. Dado que la metalografía es un método destructivo pues es necesario efectuar un pulido perfecto en un plano de la superficie para observar al microscopio la estructura del metal, y en nuestro trabajo tratamos de dañar lo menos posible las piezas a estudiar, no siempre hemos podido metalografiar las partes más significativas desde el punto de vista de la información tecnológica. Un punzón puede presentar los efectos de tratamientos mecánicos distintos en la purta y en el talón, siendo el extremo aguzado la parte a la que se suelen aplicar procesos mecánicos más complejos para darle la forma conveniente y endurecer el metal. Los tratamientos térmicos, en cambio, afectan por igual a toda la masa metálica por tratarse de piezas generalmente de tamaño pequeño. La secuencia en el taller puede definirse del siguiente modo: el primer proceso es obtener una pieza de fundición con la forma aproximada del punzón. Este producto de fundición puede emplearse directamente aguzando la punta con una piedra de afilar, o puede ser trabajado a martillo sobre un yunque adecuado para rematar su forma y aguzar los extremos. El proceso de martilleo endurece el metal, dependiendo el grado de dureza alcanzado de la mayor o menor deformación (compresión o estiramiento) conseguido, pero también lo hace más frágil. Finalmente, el recocido térmico tiene por efecto la recristalización del metal, reordenando los cristales rotos por el martilleo. Ablanda de nuevo el metal, restándole fragilidad. El grado de recristalización y el tamaño del grano conseguido dependen de la temperatura y del tiempo de exposición. En el caso del cobre, conseguir un grano de tamaño medio bien recristalizado requiere una temperatura de unos $700^{\circ} \mathrm{C}$ y un tiempo de más de media hora de exposición.

Resumimos en la Tabla 1 los resultados de las observaciones metalográficas, ordenando por su creciente complejidad los procesos de taller observados. Es evidente que los punzones calcolíticos son instrumentos producidos a molde, como demuestran los ejemplares de Los Millares y Las Angosturas, si bien por el momento se desconocen tales moldes. Aunque ningún punzón ha podido ser metalografiado en la punta, la existencia de forja en frio en el talón de alguno de ellos hace presumir que la punta llevará, como poco, el mismo tratamiento, aunque lo más probable es que el extremo activo fuera martilleado más intensamente. 


\begin{tabular}{|c|c|c|c|c|c|}
\hline \multicolumn{6}{|c|}{$\begin{array}{l}\text { Tabla } 1 \\
\text { IES CALCOLÍTICOS }\end{array}$} \\
\hline Yacimiento & $\%$ As & $\% \mathbf{S n}$ & $\% \mathrm{~Pb}$ & Tratamientos & $\begin{array}{l}\text { Zona } \\
\text { analizada }\end{array}$ \\
\hline Los Millares (AL) & 1,42 & 0,0 & 0,0 & Fundición & Cara lateral \\
\hline Las Angosturas (GR) & 1,42 & 0,0 & 0,0 & Fundición & Talón \\
\hline Las Angosturas (GR) & 2,17 & 0,13 & 0,0 & ¿Fundición? & Cara lateral \\
\hline Los Millares (AL) & 1,56 & 0,0 & 0,35 & Fundición+Forja en trio leve & Cara lateral \\
\hline Cerro de la Virgen (GR) & 2,32 & 0,0 & 0,0 & Fundición+Forja en frio leve & Talón \\
\hline Cerro de la Virgen (GR) & 1,97 & 0,0 & 0,0 & Fundición+Forja en frio leve & Talón \\
\hline Guidoiro Areoso (PO) & 1,34 & 21,5 & 0,86 & Fundición+Forja en frio & Sec. transve. \\
\hline La Esgaravita (M) & 0,0 & 0,0 & 0,0 & Fundición+Forja en frio intensa & Cara lateral \\
\hline La Esgaravita (M) & 0,93 & 0,0 & 0,0 & Fundición+Forja en frío intensa & Cara lateral \\
\hline El Gárcel (AL) & 0,75 & 0,0 & 0,0 & $\begin{array}{l}\text { Fundicion+Forja en frio+Recocido } \\
\text { insuficiente }\end{array}$ & Cara lateral \\
\hline Las Angosturas (GR) & 0,37 & 0,03 & 0,0 & $\begin{array}{l}\text { Fundición+Forja en frio+Recocido } \\
\text { insuficiente }\end{array}$ & Talón \\
\hline El Malagón (GR) & 0,48 & 0,02 & 0,0 & Fundición+Forja en frio+Recocido & Talón \\
\hline Guidoiro Areoso (PO) & 1,84 & 21,8 & 0,11 & Fundición+Forja en frio+Recocido & Sec. transve. \\
\hline
\end{tabular}

Conviene señalar que ya a lo largo del Calcolitico se lograron las técnicas de taller básicas que permiten el trabajo del cobre: la fundición, la forja en frío y el tratamiento térmico de recocido para recristalizar el metal. La secuencia temporal de introducción de estas técnicas todavia no hemos podido establecerla. Una fecha ante quem para el conjunto la da El Malagón, cuya ocupación se abandona hacia el 1900 a.C. (ARRIBAS et al. 1989: 74). El punzón estudiado de este yacimiento muestra ya el empleo de recocido térmico. Para el resto de los materiales no hay fechas radiocarbónicas asociadas (hay fechas de conjunto para los niveles calcoliticos del Cerro de la Virgen, pero, en este caso, no ayudan a concretar más). Los punzones de bronce de Guidoiro Areoso obedecen al mismo modelo que los de cobre de otras áreas de la Península.

\subsection{Los punzones del Bronce Antiguo}

El número de piezas analizadas del Bronce Antiguo computa un total de cincuenta y cinco. La información disponible sobre punzones en 
Andalucía se centra en la región de la campiña del Guadalquivir, con ocho ejemplares procedentes de los términos de Baena, Castro del Río y Porcuna. Son de cobre arsenicado, con una media de arsénico en torno al $0,84 \%$.

En la Meseta Sur contamos con dos punzones madrileños (de El Ventorro y Las Mariquitas) y uno de Cuenca (de El Vilano). Son de cobre con una media de arsénico del 0,95\%.

La Cuenca del Duero aporta diecinueve punzones a este estudio, entre ellos uno de bronce encontrado en la Cueva del Asno (Soria) ${ }^{6}$. Los de cobre vienen de yacimientos distribuidos por todas las provincias afectadas, formando un conjunto con una media de arsénico del 0,75\%. Los valores extremos oscilan entre 0,0 y $3,9 \%$.

Del País Vasco proceden otros diecinueve punzones de cobre o cobre arsenicado, la mayoria del yacimiento alavés de Cueva de Gobaederra (12 ejemplares). Buena parte de los análisis y metalografías ya fueron publicados por Valdés (1989). El contenido de arsénico oscila entre 0,0 y $1,1 \%$, con un valor medio de $0,4 \%$.

En el curso alto del Ebro, cuatro yacimientos navarros aportan otros tantos punzones de cobre, con una media de arsénico de 0,65\%.

Finalmente, en el Levante, las antiguas excavaciones de Siret en la Loma Terrera (Alberic) completan la serie con dos punzones de cobre arsenicado.

Los análisis metalográficos de siete piezas indican un claro predominio de los procesos de forja en frío de un producto de fundición y quedan resumidos en la Tabla 2. Hay alguna novedad en los tratamientos respecto de los detectados en el Calcolítico (Tabla 1): es el proceso de una nueva forja en frío tras el recocido que muestra el punzón de El Teriñuelo.

\subsection{Los punzones del Bronce Medio}

En este periodo comienzan a ser frecuentes los punzones de bronce en ciertas regiones de la Península. Asi, en la Cuenca del Duero, de vein-

6 La adscripción al Bronce Antiguo del punzón de la Cueva del Asno, en particular a una fecha radiocarbónica de 1910 a.C., según propone Eiroa (1980: 69), es muy discutida. Veanse las consideraciones hechas al respecto en Rovira, Montero y Consuegra (1992: 251-252) o en Jimeno y Fernández Moreno (1992: 240). 
Punzones y varillas metálicas en la Prehistoria reciente española...

Tabla 2

PUNZONES DEL BRONCE ANTIGUO

\begin{tabular}{lllllll}
\hline Yacimiento & $\%$ As $\%$ Sn & $\% \mathrm{~Pb}$ & Tratamientos & $\begin{array}{l}\text { Zona } \\
\text { analizada }\end{array}$ \\
\hline Cueva de Gobaederra (VI) & 0,29 & 0,02 & 0,0 & Fundición+Forja en frio & Plano lateral \\
\hline Cueva de Gobaederra (VI) & 0,0 & 0,0 & 0,0 & Fundición+Forja en frio & Plano lateral \\
\hline Cueva de Gobaederra (VI) & 0,62 & 0,01 & 0,0 & Fundición+Forja en frío & Punta \\
\hline Cueva de Gobaederra (VI) & 0,30 & 0,0 & 0,0 & Fundición+Forja en frí & Punta \\
\hline Dolmen de La Mina (VI) & 0,0 & 0,15 & 0,0 & Fundición+Forja en frio & Plano lateral \\
\hline San Pelayo (SA) & 3,95 & 0,0 & 0,0 & Fundición+Forja en frío & Plano lateral \\
\hline Dolmen de El Terinuelo (SA) & 0,48 & 0,0 & 0,0 & $\begin{array}{l}\text { Fundición+Forja en frio+Recocido } \\
+ \text { Forja en frio }\end{array}$ & Talón \\
\hline
\end{tabular}

ticuatro punzones analizados diez son de bronce con una media de estaño de $18,9 \%$. Se trata, pues, de bronces muy ricos, y aunque en algunos casos la cifra de estaño puede estar sobrevalorada debido al fuerte ataque de la corrosión metálica, hay piezas como la de Quintanadueñas (Burgos) cuyo metal sano ha dado $25,6 \% \mathrm{Sn}$. Los bronces pobres son escasos; tan sólo un ejemplar procedente de Bocos de Duero (Valladolid), con 4,9 \% Sn, entraría en esa categoria. Los catorce punzones de cobre, por su parte, muestran contenidos de arsénico que oscilan entre 0,0 y $6,0 \%$, pero el valor medio se sitúa en $0,90 \%$, por lo que las cifras superiores al $1 \%$ son excepcionales. Por desgracia aún carecemos de un buen entramado cronológico para situar la aparición del bronce en esta zona. Yacimientos como La Corvera (Salamanca) o Cueva Rubia (Palencia), con bronces de calidad y algún cobre, no han proporcionado todavía fechas absolutas. Junto a ellos, Los Tolmos de Caracena (Soria), lugar bien estudiado y con una secuencia que agota el Bronce Medio local, parece refractario a la tecnologia del bronce.

En la Meseta Sur, fuera de los territorios ocupados por el Bronce de La Mancha se han documentado trece punzones: seis de cobre con una media de $0,63 \%$ As y siete de bronce con $14,4 \%$ Sn por término medio. Dos yacimientos aportan los materiales broncíneos: la Loma del Lomo, en provincia de Guadalajara (VALIENTE 1993) y el solar de la Cooperativa del Caserío de Perales, en Madrid (BLASCO y Rovira 1992-93). En la Loma se ha obtenido una datación radiocarbónica del 1670 a.C. para un contexto con metalurgia de bronce (VALIENTE 1993: 304), gracias a la cual cabe pensar en una producción temprana de esta aleación en el Bronce Pleno del área central peninsular, y hace más plausible la hipótesis o 
modelo propuesto no hace mucho según el cual el bronce podria haber llegado a la Meseta Norte a finales del Bronce antiguo (RoviRA, MONTERO y Consuegra 1992: 256).

El Valle del Ebro aporta quince punzones, la mayoría procedentes de recientes excavaciones en Monte Aguilar I, en las Bárdenas Reales (SESMA 1991). Nueve son de bronce, predominando los bronces pobres (la media de estaño es $4,17 \%$ ), lo que confirma ciertos aspectos de la metalurgia y la circulación de metales que habían sido propuestos al estudiar los punzones oscenses de Punta Farisa (RoviRA 1989-90) ${ }^{7}$.

Fuera de estas áreas la información recogida es muy escasa y se reduce a dos punzones vascos (uno de cobre arsenicado y otro de bronce pobre), uno de Extremadura de cobre arsenicado y tres del Bajo Guadalquivir también de esa misma aleación ${ }^{8}$.

Siete punzones han sido metalografiados, manifestando los tratamientos resumidos en la Tabla 3 . Los de bronce muestran una cadena de procesos de fabricación más compleja que los de cobre, aunque esta cadena ya comenzaba a percibirse en las piezas de cobre del Bronce Antiguo (véase la Tabla 2).

Se han encontrado moldes para la fundición de punzones en el yacimiento alicantino de Cabezo Redondo. Es importante señalar, sin embargo, que algunas de las valvas clasificadas como moldes (SOLER 1987: 192, figs. 1-4) no parece que pudieran servir como tales. La falta de bebedero y fondo en piezas completas nos induce a pensar que se trata más bien de posibles afiladeras o pulidores. Piedras iguales halladas en superficie en el yacimiento de la Edad del Bronce de La Parra de las Vegas (Cuenca) fueron ya en su dia clasificadas también como afiladeras (PÉREZ Ortiz y RuIz ARGILÉs 1976: 270) y recogidas posteriormente como alisadores por Martínez Navarrete y Valiente Cánovas (1983: 148, lám. VI, a). Otras dos piezas similares, una del yacimiento protocogotas de Perales del Rio (Madrid) ${ }^{9}$ y otra de la Morra del Quintanar (Albacete), también parecen ser alisadores y no verdaderos moldes.

Monte Aguilar es un yacimiento con materiales que evidencian la práctica de la metalurgia. Los objetos de bronce (no sólo los punzones) manifiestan el predominio de aleaciones con proporciones bajas de estaño, siendo relativamente abundantes las piezas de cobre o cobre arsenicado. La dificultad para un buen abastecimiento de estaño y la recurrencia al reciclado de metal amortizado explicarían estos bronces pobres.

Estos punzones provienen de uno o varios enterramientos en un hipogeo de la necropolis Las Cumbres, junto al Castillo de Doña Blanca, en cuyos ajuares hay tam bién piezas de bronce. La cronología podria ser de finales del Bronce Medio o comienzos del Tardío. Véase al respecto (ROVIRA, e.p. y Rovira y MONTERo, e.p.).

9 Agradecemos esta información a doña Juana Calle. 
Punzones y varillas metálicas en la Prehistoria reciente española...

\begin{tabular}{|c|c|c|c|c|c|}
\hline \multicolumn{6}{|c|}{ Tabla 3} \\
\hline Yacimiento & $\%$ As & $\% \mathbf{S n}$ & $\% \mathrm{~Pb}$ & Tratamientos & $\begin{array}{l}\text { Zona } \\
\text { analizada }\end{array}$ \\
\hline Monte Aguilar I (NA) & 0,88 & 0,06 & 0,0 & Fundición+Forja en frio leve & Talón \\
\hline Cueva Pedro Fernández (M) & 1,11 & 0,0 & 0,32 & Fundición+Forja en frio & Talón \\
\hline Los Tolmos (SO) & 0,0 & 0,0 & 0,0 & Fundición+Forja en frío & Talon \\
\hline Caserio de Perales (M) & 1,22 & 20,0 & 0,26 & Fundición+Forja en frio+Recocido & Talón \\
\hline Caserio de Perales $(\mathrm{M})$ & 0,19 & 16,0 & 0,0 & $\begin{array}{l}\text { Fundición+Forja en frío } \\
+ \text { Recocido+Forja en frio leve }\end{array}$ & Talón \\
\hline Monte Aguilar I (NA) & 0,0 & 12,4 & 0,0 & $\begin{array}{l}\text { Fundición+Forja en frio } \\
+ \text { Recocido+Forja en frio leve }\end{array}$ & Talón \\
\hline Loma del Lomo (GU) & 0,0 & 0,02 & 0,0 & $\begin{array}{l}\text { Fundición+Forja en frí } \\
\text { +Recocido+Forja en frio leve }\end{array}$ & Talón \\
\hline
\end{tabular}

\subsection{Los punzones argáricos}

Un total de veintidós punzones han sido manejados en este estudio. La imposibilidad de asignarles una fase precisa dentro de la cultura de El Argar obliga a considerarlos como un solo conjunto (véase nota 4). Veinte punzones son de cobre o cobre arsenicado, con un valor medio del 1,3\% As y una desviación típica también de 1,3 indicando una fuerte dispersión de los valores respecto de la media. Los dos punzones restantes son de bronce pobre: uno del Cerro de la Campana (Yecla), con $3,8 \%$ Sn y $0,4 \%$ As, y el otro de El Oficio (Cuevas del Almanzora), con $1,2 \%$ Sn y $1,4 \%$ As. Ambos, pero sobre todo el segundo, sugieren el empleo de cobres típicos de la zona (habitualmente arsenicados) a los que se une una pequeña cantidad de estaño. La intencionalidad de estas aleaciones es más que dudosa pues, desde el punto de vista estrictamente tecnológico, este pequeño porcentaje de estaño apenas modifica las cualidades mecánicas del cobre. No obstante, están indicando que en algún momento (probablemente avanzado) llegaron al Sureste objetos de bronce y su correspondiente tecnología ${ }^{10}$.

10 Como ya hizo notar Montero (1992: 473 y ss.), la mayor parte de los bronces argáricos hasta ahora analizados son objetos de adorno. predominando los bronces pobres. No parece apreciarse, en principio, el interés tecnológico de la nueva aleación, sino su valor como elemento de prestigio. Ello unido a! conocimiento que se va teniendo del panorama peninsular, hace pensar en una introducción tardia del bronce al estaño en el Sureste, en fechas tentativas del 1500-1400 a.C. 
Los resultados de la metalografía de cuatro punzones de esta serie se resumen en la Tabla 4 . En ella queda expuesto cierto cambio en las técnicas de taller con relación a las piezas calcolíticas (véase la Tabla 1), haciéndose más frecuente el tratamiento final de forja en frío, lo cual redunda en una mejora real del producto pues endurece el cobre recocido.

Al yacimiento de El Argar pertenecen algunos moldes de varillas cuadrangulares (SIRET 1890: lám. 27).

Tabla 4

PUNZONES ARGÁRICOS DEL SURESTE

\begin{tabular}{lccclll}
\hline Yacimiento & $\%$ As $\%$ Sn $\%$ Pb & Tratamientos & $\begin{array}{l}\text { Zona } \\
\text { analizada }\end{array}$ \\
\hline Peñón de la Reina (AL) & 1,4 & 0,03 & 0,0 & Fundición & Talón \\
\hline Cerro de Enmedio (AL) & 1,3 & 0,0 & 0,0 & $\begin{array}{l}\text { Fundición+Forja en frio } \\
\text { +Recocido+Forja en frio leve }\end{array}$ & Talón \\
\hline Hoya de Castellones (GR) & 0,0 & 0,0 & 0,0 & $\begin{array}{l}\text { Fundición+Forja en frí } \\
\text { +Recocido+Forja en frio leve }\end{array}$ & Talón \\
\hline Hoya de la Matanza (AL) & 0,9 & 0,0 & 0,0 & $\begin{array}{l}\text { Fundición+Forja en frio } \\
\text { +Recocido+Forja en frio leve }\end{array}$ & Talón \\
\hline
\end{tabular}

\subsection{Los punzones del Bronce de la Mancha}

Disponemos de los análisis de treinta y cinco punzones procedentes de varios yacimientos característicos del Bronce de la Mancha, siendo los que han aportado un mayor número El Acequión, El Cerro de la Encantada, Santa María del Retamar y El Cerro del Cuco. En función de las dataciones calibradas de algunos de estos yacimientos, El Acequión se perfila como uno de los más antiguos, con fechas medias que oscilan entre el 2200 y el 1950 cal. a.C. (dentro del Bronce Antiguo calibrado de otras regiones). El Cerro de la Encantada, con fechas comprendidas entre el 2380 y el 1550 cal. a.C. abarcaria Bronce Antiguo y Medio. En ese margen cronológico de Bronce Antiguo y Pleno se mueven los materiales estudiados aquí.

Sólo uno de los punzones presenta estaño en cantidad valorable $(1,4 \%)$; pertenece al conjunto de Santa María del Retamar ${ }^{11}$, del que hay

1 Es un punzón con una composición un tanto atípica no sólo dentro del conjunto del propio yacimiento, pues junto a ese $1,4 \%$ de estaño tenemos $3,6 \%$ de arsénico 
Punzones y varillas metálicas en la Prehistoria reciente española...

fechas del 1950-1870 cal. a.C., aunque ignoramos si la pieza pertenece a los estratos fechados o se encontró fuera de ellos. Las restantes son piezas de cobre o cobre arsenicado, con un valor medio del 1,6\% As (los valores oscilan entre 0,0 y $4,4 \%$ ).

Ocho punzones han sido sometidos a estudios metalográficos, con los resultados expresados en la Tabla 5 . En ellos podemos ver que predomina el "modo calcolitico" de producción, a excepción de un ejemplar de Santa María del Retamar cuya factura es similar a la mayoría de los punzones de la Tabla 4.

Tabla 5

PUNZONES DEL BRONCE DE LA MANCHA

\begin{tabular}{l|lllll}
\hline Yacimiento & $\%$ As $\%$ Sn $\%$ Pb & Tratamientos & $\begin{array}{l}\text { Zona } \\
\text { analizada }\end{array}$ \\
\hline El Acequión (AB) & 0,72 & 0,0 & 0,0 & Fundición & Talón \\
\hline El Acequión (AB) & 0,28 & 0,0 & 0,0 & Fundición+Forja en frio & Talón \\
\hline El Acequión (AB) & 1,55 & 0,23 & 0,75 & Fundición+Forja en frío & Talón \\
\hline El Acequión (AB) & 3,92 & 0,0 & 0,0 & Fundición+Forja en frío & Punta \\
\hline Cerro de la Encantada (CR) & 0,72 & 0,03 & 0,25 & Fundicion+Forja en frio & Talón \\
\hline Cerro del Bu (TO) & 4,02 & 0,02 & 0,0 & Fundición+Forja en frío & Talón \\
\hline Cerro del Cuco (CU) & 3,14 & 0,0 & 0,0 & Fundición+Forja en frio & Talón \\
\hline Sta. Maria del Retamar (CR) & 1,82 & 0,0 & 0,0 & $\begin{array}{l}\text { Fundición+Forja en frio } \\
\text { +Recocido+Forja en frio }\end{array}$ & Talón \\
\hline
\end{tabular}

\subsection{Punzones y varillas del Bronce Tardio y Final}

A partir de este momento al conjunto de punzones se une el estudio de otras piezas afines: las varillas de metal. Comenzaremos revisando los punzones.

(es uno de los más arsenicados de la región manchega) y 1,1\% de plomo. Los Montes de Toledo son prolijos en mineralizaciones complejas de cobre, pero aquellas que asocian cobre con arsénico, estaño y plomo, que podrian justificar una aleación con tales características, no abundan. Entre las minas hasta ahora investigadas sólo el Cerro de la Mina (Totanés) y El Guijo (Mazarambroz) podrian apuntarse como candidatas (véase MONTERo et al. 1990: 49-50). La información disponible sobre los metalotectos cupriferos manchegos es aún bastante limitada, por lo que la intención de este comentario va más en el sentido de justificar la posibilidad de que se trate de una aleación natural que hacia una indicación de la posible procedencia de los recursos naturales empleados. 
En el Sureste la muestra de materiales para este período es muy reducida, limitándose a cuatro ejemplares procedentes de El Peñón de la Reina (Alboloduy), estudiados hace algunos años por Rovira y Sanz (1983). Tres de ellos son de cobre o cobre arsenicado y el cuarto de bronce con $10,7 \% \mathrm{Sn}$ y $0,6 \% \mathrm{~Pb}$. Del resto de Andalucia no tenemos datos referidos a punzones.

De la Meseta Sur y sus aledaños se han analizado tres punzones, todos de sección cuadrada. El más antiguo viene de un contexto del Bronce Tardio de El Castelión (Hellín) y es un bronce pobre con 6,6\% Sn. Los dos restantes, del Bronce Final, son del Caserio de Perales (Madrid), con 6,1 y $15,5 \%$ Sn respectivamente (BLASCO y RovIRA 199293: 411).

En la Cuenca del Duero, de trece punzones, un ejemplar es de cobre y los demás de bronce, oscilando la cantidad de estaño entre $2,4 \%$ y $20,8 \%$, con una media de $14,5 \%$. Son piezas en general poco plomadas, pues sólo tres superan el $1 \%$ de plomo, pero no llegan a rebasar el $2 \%$.

Del País Vasco tenemos datos de un único punzón procedente del Puerto de Herrera (Alava), con $14,6 \%$ Sn.

El Valle del Ebro limita su aportación a este estudio a dos ejemplares del depósito inédito del Monderes (Huesca), ambos ricos en estaño y uno de ellos con $3,4 \% \mathrm{~Pb}$.

El Bronce Final del Noreste está representado por seis punzones de los yacimientos ilerdenses de Genó y Redó. En todos los casos son bronces con tasas de estaño que oscilan entre 4,5 y $16,0 \%$, dando una media de $11.5 \%$.

Finalmente, de las tierras levantinas hemos analizado dos punzones, uno de la Mola d'Agres (Alicante), con 14,0 \% Sn y el otro del Pic dels Corbs (Sagunto) con 7,8\%.

En una visión de conjunto, aunque con datos ciertamente escasos en volumen, podria concluirse que durante este periodo predominan netamente los punzones de bronce binario, y los pocos que contienen plomo muestran cifras que apenas superan el $2 \%$. También se siguen empleando punzones de cobre, aunque su número parece pequeño en relación con los de bronce.

El estudio metalográfico de cuatro piezas, cuyos resultados se sintetizan en la Tabla 6 , indican forjado y recocido sistemático del metal, con algún tratamiento final de forja en frío. 
Punzones y varillas metálicas en la Prehistoria reciente española...

\section{Tabla 6}

\section{PUNZONES DEL BRONCE TARDÍO Y FINAL}

\begin{tabular}{lccccc}
\hline Yacimiento & $\%$ As $\%$ Sn $\%$ Pb & Tratamientos & $\begin{array}{l}\text { Zona } \\
\text { analizada }\end{array}$ \\
\hline El Peñón de la Reina (AL) & 0,0 & 10,7 & 0,65 & Fundición & Talón \\
\hline Caserio de Perales (M) & 0,0 & 6,1 & 0,15 & Fundición+Forja en frio+Recocido & Talón \\
\hline Caserio de Perales (M) & 0,0 & 15,5 & 2,1 & Fundición+Forja en frio+Recocido & Talón \\
\hline Mola d'Agres (A) & 0,0 & 14,1 & 0,0 & $\begin{array}{l}\text { Fundición+Forja en frío } \\
\text { +Recocido+Forja en frio }\end{array}$ & Plano lateral \\
\hline
\end{tabular}

Las varillas metálicas son objetos frecuentes entre los hallazgos del Bronce Final. En algunos casos se pueden confundir con fragmentos de punzones, pero en otros, la mayoría, los remates de sus extremos sin signos de fractura indican con poco margen de error que son varillas 0 barretas de metal. Sus secciones, similares a las de los punzones, las emparentan con estos instrumentos.

De Andalucia hemos analizado dos varillas, una de la Cruz del Negro (Carmona), de cobre, y otra de Torre Alta (Priego), de bronce pobre con $4,3 \% \mathrm{Sn}$.

En La Mancha, el yacimiento de Hoyas del Castillo (Pajaroncillo, Cuenca) ha proporcionado cinco varillas en un contexto de Bronce Tardio y Final ${ }^{12}$. Son bronces aparentemente ricos en estaño (entre 18,1 y $27,8 \%$ ), pero el avanzado estado de oxidación del metal aconseja tomar con precaución estos resultados, cuyos valores originales probablemente no superaban el $15 \%$.

Otras dos varillas, del yacimiento leonés de El Castro (Gusendo de los Oteros) fechado en la transición Bronce Final-Hierro, constituyen la aportación de la Cuenca del Duero a este estudio. Ambas son de bronce pobre con menos del $3 \% \mathrm{Sn}$.

Con una cronologia similar a la antedicha, el Castro de Torroso en Pontevedra ha dado una varilla de bronce con $17 \%$ Sn y $4 \% \mathrm{~Pb}$ (PEÑA 1992: 124). No hay más datos del Noroeste.

12 Este yacimiento ha sido dado a conocer por Ulreich, Negrete y Puch (1993). Recientemente Ignacio Montero ha preparado un informe sobre los análisis espectrográficos de los metales, para los citados autores, que es de esperar sea publicado en breve. 
De la cornisa cantábrica, recientes análisis de los materiales metálicos de la Cueva de Arenaza I (Vizcaya) han permitido conocer la composición de seis varillas recogidas en niveles del Bronce Final. Son bronces ricos en estaño (14,3\% de media), dos de ellos con algo de plomo.

Los datos disponibles del Valle del Ebro se limitan a cuatro varillas del depósito del Monderes, también de bronce rico, con valores que oscilan entre 13,1 y $15,4 \%$. Dos, de sección plano-convexa, podrían ser fragmentos de barretas para fabricar pulseras.

Finalmente, los yacimientos levantinos de la Mola d'Agres y Pic dels Corbs reúnen un total de cinco varillas de bronce de buena calidad, con una media de estaño del $15,4 \%$.

Disponemos de ensayos metalográficos de cinco varillas, cuyos resultados se anotan en la Tabla 7. Los procesos de taller observados son similares a los encontrados en los punzones coetáneos (véase la Tabla 6), si bien aquí parece más frecuente un trabajo de forja en frío final para rematar la forma del objeto o conferirle determinadas cualidades mecánicas.

\section{Tabla 7}

VARILLAS DEL BRONCE FINAL

\begin{tabular}{|c|c|c|c|c|c|}
\hline Yacimiento & $\%$ As & $\% \mathbf{S n}$ & $\% \mathrm{~Pb}$ & Tratamientos & $\begin{array}{l}\text { Zona } \\
\text { analizada }\end{array}$ \\
\hline Pic dels Corbs $(V)$ & 0,0 & 13,9 & 0,0 & Fundición+Forja en frío+Recocido & Sección \\
\hline Pic dels Corbs $(\mathrm{V})$ & 0,0 & 13,5 & 0,0 & $\begin{array}{l}\text { Fundición+Forja en frío } \\
+ \text { Recocido+Forja en frio leve }\end{array}$ & Sección \\
\hline Pic dels Corbs $(\mathrm{M})$ & 0,0 & 13,5 & 0,0 & $\begin{array}{l}\text { Fundición+Forja en frío } \\
\text { +Recocido+Forja en frio }\end{array}$ & Sección \\
\hline Pic dels Corbs $(V)$ & 0,0 & 12,9 & 0,0 & $\begin{array}{l}\text { Fundici ón+Forja en frio } \\
\text { +Recocido+Forja en frío }\end{array}$ & Sección \\
\hline Mola d'Agres (A) & 0,0 & 18,3 & 0,11 & $\begin{array}{l}\text { Fundición+Forja en frío } \\
\text { +Recocido+Forja en frío }\end{array}$ & Sección \\
\hline Mola d'Agres $(A)$ & 0,0 & 18,2 & 0,0 & $\begin{array}{l}\text { Fundición+Forja en frio } \\
+ \text { +Recocido+Forja en frio }\end{array}$ & \\
\hline
\end{tabular}

\subsection{Punzones y varillas de la Edad del Hierro}

En este período parecen ser más abundantes las varillas metálicas que los punzones en los registros arqueológicos, siendo un reflejo más 
Punzones y varillas metálicas en la Prehistoria reciente española...

de los cambios estructurales acaecidos en las sociedades peninsulares con el advenimiento de la Edad del Hierro ${ }^{13}$ cuya explicación habrá que buscar. Efectivamente, y aun considerando los sesgos relativos a la selección de materiales para ser analizados, la serie que aquí presentamos está formada por veinticinco punzones y cincuenta y tres varillas.

Contamos con abundante información sobre punzones de la Meseta Sur (en particular de la franja septentrional). La Muela de Alarilla (Guadalajara) es el yacimiento con mayor número de análisis, diez, todos ellos de bronces conteniendo estaño entre 12,0 y 21,2 \%. Cinco punzones muestran aleaciones ternarias cobre-estaño-plomo, aunque sólo dos son realmente plomados $(4,7$ y $10,6 \% \mathrm{~Pb}$ respectivamente). El resto, hasta un total de 16 piezas, lo proporcionan varios yacimientos castellano-manchegos. Desde el punto de vista cualitativo, un punzón es de cobre ${ }^{14}$ y los demás de bronce; la media calculada de estaño es del $12,29 \%$.

De la Cuenca del Duero hay analizados cinco punzones de este período, tres de los cuales son de cobre y dos de bronce, uno de ellos (de Bedunia, León) muy plomado $(10,5 \% \mathrm{~Pb})$.

Rematan la serie cuatro punzones de yacimientos alaveses (Castillo de Henayo y Castro de Kutzemendi), de bronce con un contenido medio de estaño del $16,8 \%$.

Las cuatro piezas metalografiadas muestran los tratamientos de taller resumidos en la Tabla 8 . Una pieza conserva la estructura dentrítica ligeramente deformada en los bordes, certificando su manufactura a molde. Las demás, con idénticos tratamientos, indican que el procedimiento habitual fue martillear y recocer el metal.

Las varillas metálicas ofrecen una distribución territorial mayor que los punzones, hecho que debe atribuirse más al modo de confeccionar esta muestra que al paisaje real, pues es sabido que los punzones son instrumentos muy comunes todavia en esta época.

\footnotetext{
13 Esta idea no surge del cómputo simple de los materiales analizados, sino de su procedencia contextual. Asi, por ejemplo, en las series completas de metales analizados de Medellin hay 12 varillas y ningún punzón; en Ceremeño tenemos cuatro fragmentos de varilla y ningún punzón; en el Cerro de las Nieves, tres varillas y un punzón; en Soto de Medinilla, tres varillas y dos punzones. En la Muela de Alarilla, en cambio, 10 punzones y ninguna varilla (aunque hay tres fragmentos que podrian serlo).

${ }_{14}$ Procede de El Amarejo (Albacete), de la serie publicada en Rovira, Consuegra y Montero (1989: 103). Los bronces de El Amarejo son frecuentemente pobres en estaño, a excepción de las posibles importaciones.
} 
Tabla 8

PUNZONES DE LA EDAD DEL HIERRO

\begin{tabular}{lllllll}
\hline Yacimiento & $\%$ As $\%$ Sn $\%$ Pb & Tratamientos & $\begin{array}{l}\text { Zona } \\
\text { analizada }\end{array}$ \\
\hline Muela de Alarilla (GU) & 0,0 & 21,2 & 0,42 & Fundición+Forja en frio leve & Talón \\
\hline Muela de Alarilla (GU) & 0,38 & 15,5 & 0,49 & Fundición+Forja en frio+Recocido & Talón \\
\hline Muela de Alarilla (GU) & 0,71 & 13,0 & 0,86 & Fundición+Forja en frio+Recocido & Talón \\
\hline Castro de Kutzemendi (VI) & 0,0 & 12,4 & 1,34 & Fundición+Forja en frio+Recocido Talón \\
\hline
\end{tabular}

Las cinco varillas ${ }^{15}$ andaluzas analizadas proceden de yacimientos onubenses (Rovira, Consuegra y Montero 1987; Fernández JuRAdo 198889). Uno de los análisis corresponde en realidad a un haz de obeloi hallado en las excavaciones del solar de la calle Méndez Núñez, 5, de Huelva. Exceptuando una pieza de cobre y otra de bronce con $13,6 \% \mathrm{Sn}$, el resto son bronces muy pobres.

Del yacimiento orientalizante de Medellín (Badajoz) hemos analizado doce varillas de bronce, dadndo una media de estaño del 10,5\%. Tres de ellas son bronces muy pobres.

De las dieciocho varillas procedentes de la Meseta Sur, tres son de cobre. La media de estaño en las de bronce es del $12,3 \%$, pero conviene señalar que se observan grandes diferencias entre las aleaciones del mundo ibérico (Castillo de Alarcos, Cerro de las Nieves, El Amarejo), netamente más pobres en estaño, y las de yacimientos del ámbito celtibérico (Ceremeño, Ecce Homo, Muela de Alarilla).

La Cuenca del Duero aporta veiritiún análisis de varillas, catorce de los cuales se han tomado a piezas de la necrópolis de Las Ruedas (Padilla de Duero) ${ }^{16}$. Dos ejemplares son de cobre, obteniendo en los restantes una media de estaño del $14,7 \%$.

De la cornisa cantábrica hemos reunido cinco análisis de varillas de bronce, con $12,0 \%$ de contenido medio de estaño.

15 Dos de estas varillas podrian haber sido instrumentos, pues una presenta un aplanamiento asimétrico en un extremo semejante al filo de un formón y la otra una punta ligeramente aguzada (véanse los dibujos en Rovira, Consuegra y Montero, 1987: 231, núms. 2 y 5 ).

${ }_{16}$ Algunas varillas de esta necrópolis muestran decoración o han sido torneadas, signos evidentes de que formaban parte de objetos más complejos. No se han tomado en cuenta en este estudio. 
Sólo dos piezas catalanas, ambas procedentes de llla d'en Reixac (Ullastret), han podido ser estudiadas por ahora. Una es de cobre y la otra de bronce ternario con $20,0 \% \mathrm{Sn}$ y $13,7 \% \mathrm{~Pb}$.

Finalmente, los yacimientos ibéricos valencianos proporcionan cuatro varillas de bronce con una tasa media del 5,9\% Sn, insistiendo de nuevo en la pobreza de los bronces ibéricos ya comentada antes.

La información metalográfica disponible se limita a las dos piezas inventariadas en la Tabla 9. La fundición como proceso elaborador primario y el trabajo de forja y recocido quedan asi recogidos, en un modelo de actuación similar al de los punzones contemporáneos.

Parejo a la abundancia de varillas es el hallazgo de moldes para su fabricación. Raure! (1976: 116 y ss.) recogió un inventario de los moldes aparecidos hasta la fecha de edición en algunos yacimientos emblemáticos del Hierro Antiguo como Cortes de Navarra, Las Peñas de Oro, Kutzemendi, etc. Tenemos, sin embargo, nuestras reservas sobre dos piedras halladas en Vélez Blanco, Almería (RaURet 1976: lám. XVIi), de cronologia incierta, y muy parecidas a las afiladeras señaladas anteriormente.

\section{Tabla 9}

VARILLAS DE LA EDAD DEL HIERRO

\begin{tabular}{|c|c|c|c|c|c|}
\hline Yacimiento & $\%$ As & $\% \mathbf{S n}$ & $\% \mathrm{~Pb}$ & Tratamientos & $\begin{array}{l}\text { Zona } \\
\text { analizada }\end{array}$ \\
\hline Castro de Kutzemendi (VI) & 0,0 & 1,56 & 0,0 & Fundición & Extremo \\
\hline Illa d'en Reixac (GE) & 0,0 & 20,0 & 13,7 & Fundición+Forja en frio+Recocido & Extremo \\
\hline
\end{tabular}

\section{ESTUDIOS COMPARATIVOS Y DISCUSIÓN}

A pesar de la descompensación en los tamaños de las muestras estadísticas que barajamos, podemos abordar algunos estudios comparativos buscando semejanza o diferencias tecnológicas entre periodos $y / o$ regiones en aquellos casos en los que el volumen de información permite conclusiones fiables. Los conjuntos se han caracterizado por la tendencia central del arsénico o del estaño, estudiando la significación de las diferencias de media ${ }^{17}$. Valgan como ejemplo las dos regiones que se anotan a continuación.

\footnotetext{
17 Para los cálculos se ha utilizado el paquete estadístico Statgraphics, versión 5
} 
En el Sureste, los punzones calcolíticos y argáricos dan medias de arsénico de 1,9 y $1,4 \%$ respectivamente, cuya diferencia no es significativa $(\mathrm{t}=1,04, \mathrm{n}=114, \alpha=0,01)$.

En la Meseta Sur, la suma de punzones calcolíticos y del Bronce Antiguo ofrece una media de arsénico de $0,7 \%$, y los del Bronce Medio $0,6 \%$, diferencia no significativa $(t=0,31, n=12, \alpha=001)$. La comparación del primer grupo con los punzones de yacimientos del Bronce de la Mancha, cuya media es $1,6 \%$ de As, tampoco acusa una diferencia con significación estadística ( $t=1,68, n=44, \alpha=0,01)$.

De los varios conjuntos y combinaciones estudiados sólo hemos encontrado diferencias significativas entre los punzones de las fases más antiguas de la Cuenca del Duero y los calcolíticos del Sureste $(t=2,72$, $n=119, \alpha=0,05)$, resultando los primeros menos arsenicados por término medio que los segundos (0,6 versus $1,9 \%$ de As). La figura 1 expresa gráficamente el comportamiento de los valores medios de arsénico de los punzones en las diversas regiones.

Sin embargo, las impurezas de arsénico no son en sí mismas buen indicador de cambios o diferencias tecnológicas. Resulta mucho más

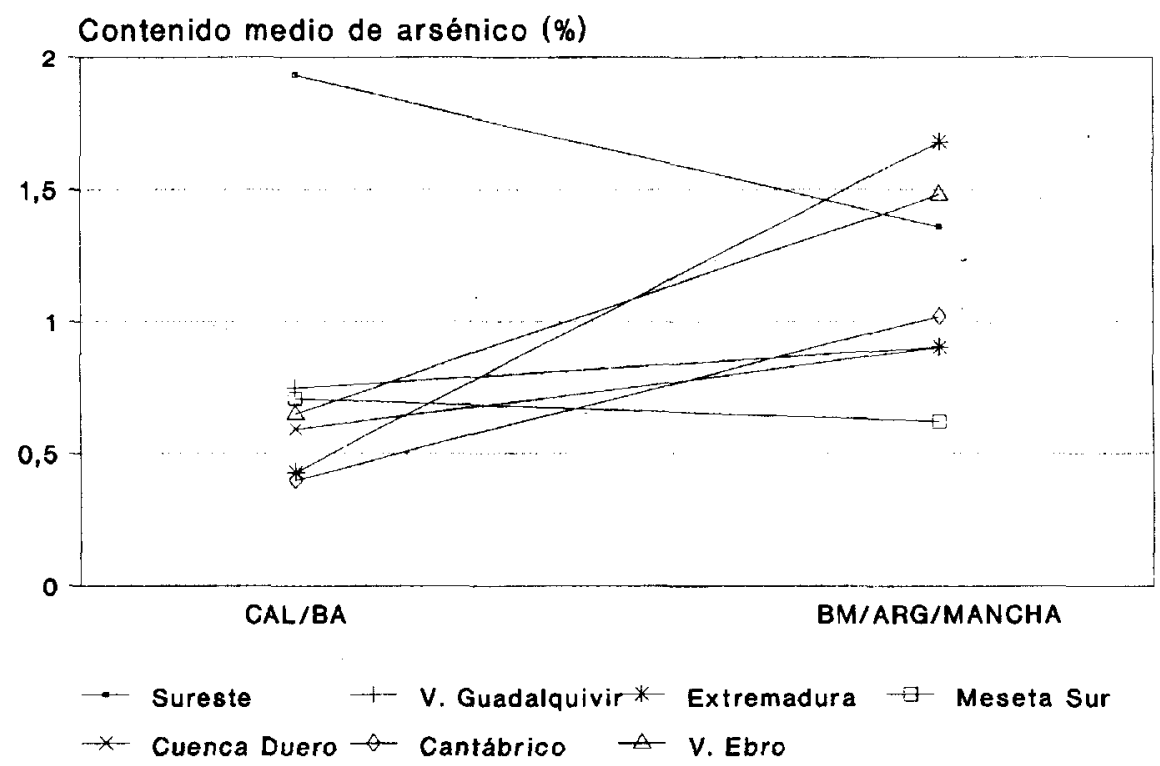

Fig. 1. Comportamiento del valor medio de arsénico en los punzones de cobre de varias regiones españolas entre el Calcolitico/Bronce Antiguo y el Bronce Medio. 
relevante observar el grado de implantación de la aleación cobre-estaño. Así, en la parte de la Meseta Sur que queda fuera del hinterland del Bronce de La Mancha, entre el Bronce Antiguo y Medio se detecta el enorme contraste entre una tecnologia de trabajo del cobre y otra de nueva implantación que produce bronces de buena calidad, aunque haya perduraciones de la primera. Lo mismo cabría decir, con sus peculiaridades, de las Cuencas del Duero y del Ebro. En cambio, las costas levantinas, la Meseta meridional y Andalucía constituyen mundos alejados de los circuitos de circulación de los bronces peninsulares más tempranos. Los punzones más ricos en estaño se manifiestan en el Bronce Medio de la Cuenca del Duero y las provincias limítrofes de Madrid y Guadalajara, como muestra la figura 2. Frente a esto la franja cantábrica y el Valle del Ebro han dado para este momento bronces pobres. Las tendencias se modificaron con el tiempo.

Si las aleaciones de los punzones reflejan situaciones de cambio tecnológico, no son tan explícitos los procesos de taller empleados en su fabricación. La cadena productiva fundición+forja en frio+recocido se reconoce ya en el Calcolítico, si bien la mayoría de los punzones de dicho periodo se quedaron en los dos primeros eslabones (Figuras 3, 4 y 5).

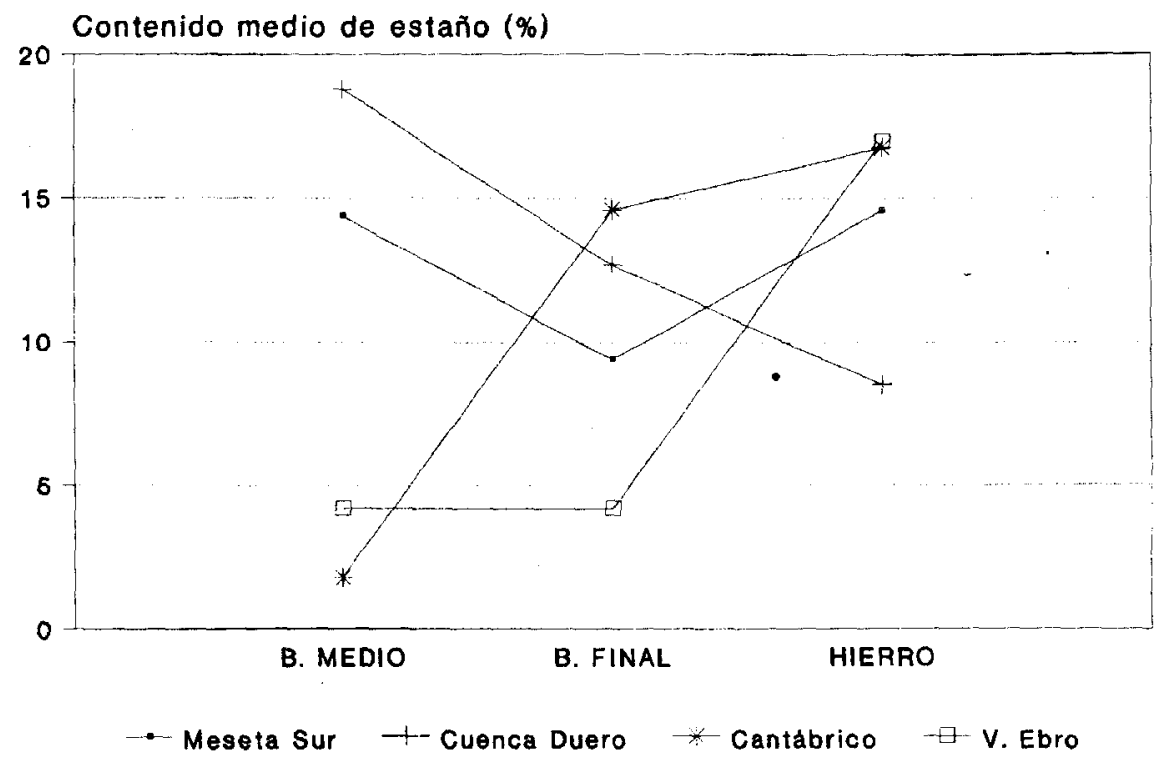

Fig. 2. Comportamiento del valor medio de estaño en los punzones de bronce de varias regiones españolas entre el Bronce Medio y la Edad del Hierro. No se han computado los ejemplares de cobre de dichos periodos. 
En el Bronce Antiguo y Medio la mecánica será en gran medida como la calcolítica (en particular en La Mancha), aunque hay que anotar la adición de un nuevo procedimiento consistente en un tratamiento final de forja en frio (Figura 6) que no es sino un retorno a las condiciones previas al recocido ${ }^{18}$.

Lo más curioso es que la serie de procesos de taller cae en pasos contradictorios ya desde el principio. Forja en frío y recocido son dos tratamientos de efectos opuestos en el cobre y sus aleaciones. El primero endurece y hace frágil el metal, y el segundo provoca una recu-

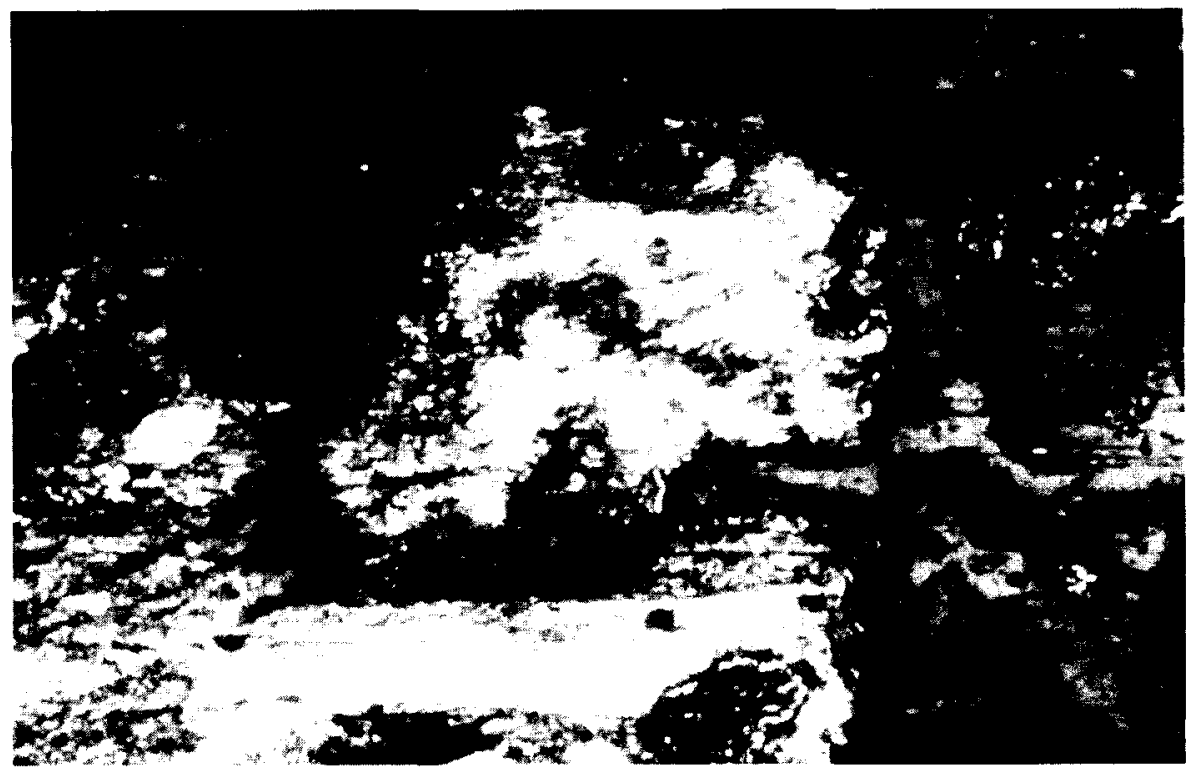

Fig. 3. Estructura metalográfica de un punzón de Los Millares (Almeria). EI pulido se ha efectuado sobre una de las caras, y revela la estructura dendritica de fundición de un cobre arsenicado $(1,4 \% A s)$, con los espacios interdendríticos muy atacados por la corrosión. No se aprecia deformación mecánica, por lo que esta parte de la pieza no recibió ningún tratamiento de martilleo tras ser sacada del molde. Ataque con persulfato e hidróxido amónico.

$55 x$.

18 En términos de resistencia mecánica esto no es estrictamente cierto, pues hay algunas diferencias entre forjar una estructura de bruto de colada (fundición) y una estructura de recocido. El recocido homogeniza la composición del metal (dentro de ciertos límites en el caso de los bronces) y el producto resultante es mejor en términos generales. Pero tal mejora es poco perceptible dentro de las prestaciones que proporcionaría el utillaje metálico prehistórico. 


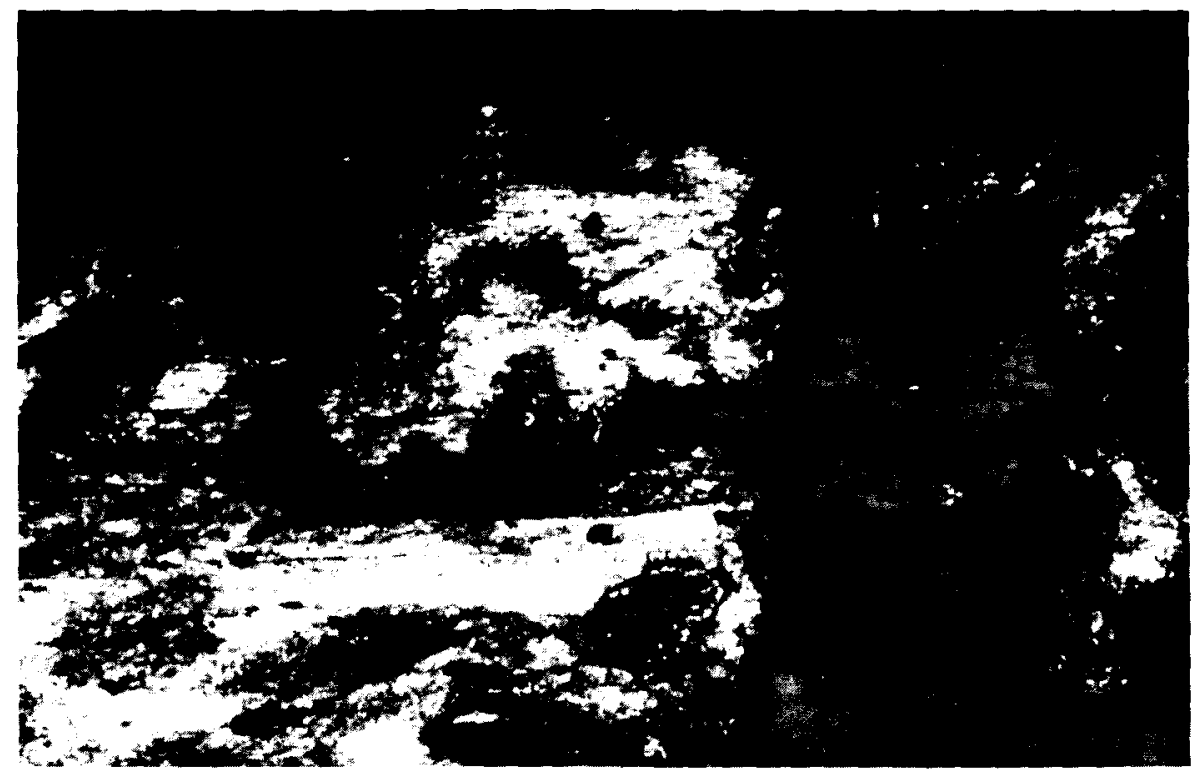

Fig. 4. Estructura metalográfica de un punzón de La Esgaravita (Alcalá de Henares. El pulido se ha efectuado sobre una de las caras y revela la estructura fibrosa del tratamiento de martilleo en frío de un cobre arsenicado $10,9 \%$ As). La distribución en fibras claras y oscuras es debida a la estructura dendritica de fundición original, aplastada por un tratamiento de forja que ha provocado una reducción por compresión del espesor del metal en más del $50 \%$, con el consiguiente alargamiento. Ello significa que la pieza en estado bruto de colada debia ser algo más del doble de gruesa o, lo que es lo mismo, que las dimensiones del objeto acabado son muy diferentes a las del molde del que procedia. Ataque con cloruro férrico y ácido clorhidrico. $75 x$.

peración de la estructura alterada por la forja, lo hace de nuevo dúctil, maleable y blando, y reduce o elimina la fragilidad. Esta alternancia de martilleo y recocido es quizá una herencia del más antiguo método de laminado del oro y del cobre en el Neolítico final/Calcolítico inicial de ciertas regiones en las que los metales nativos parecen jugar un papel decisivo en el temprano desarrollo de la metalurgia, y caracterizaría una fase premetalúrgica de aprovechamiento de metales nativos, poco conocida en general, aunque ya detectada en algunos sitios (KATINCAROV 1989; Maddin, Stech y Muhly 1991). Sin querer entrar a fondo en el análisis de estos procesos contradictorios, conviene recordar que el tratamiento térmico hace perder arsénico al cobre arsenicado (MCKERRELL y TYLECOTE 1972). Por tanto, tras el recocido el metal es menos duro por dos razones: 1) porque la recristalización genera una nueva estructura interna más blanda, y 2) porque la pérdida de arsénico produce una aleación tam- 


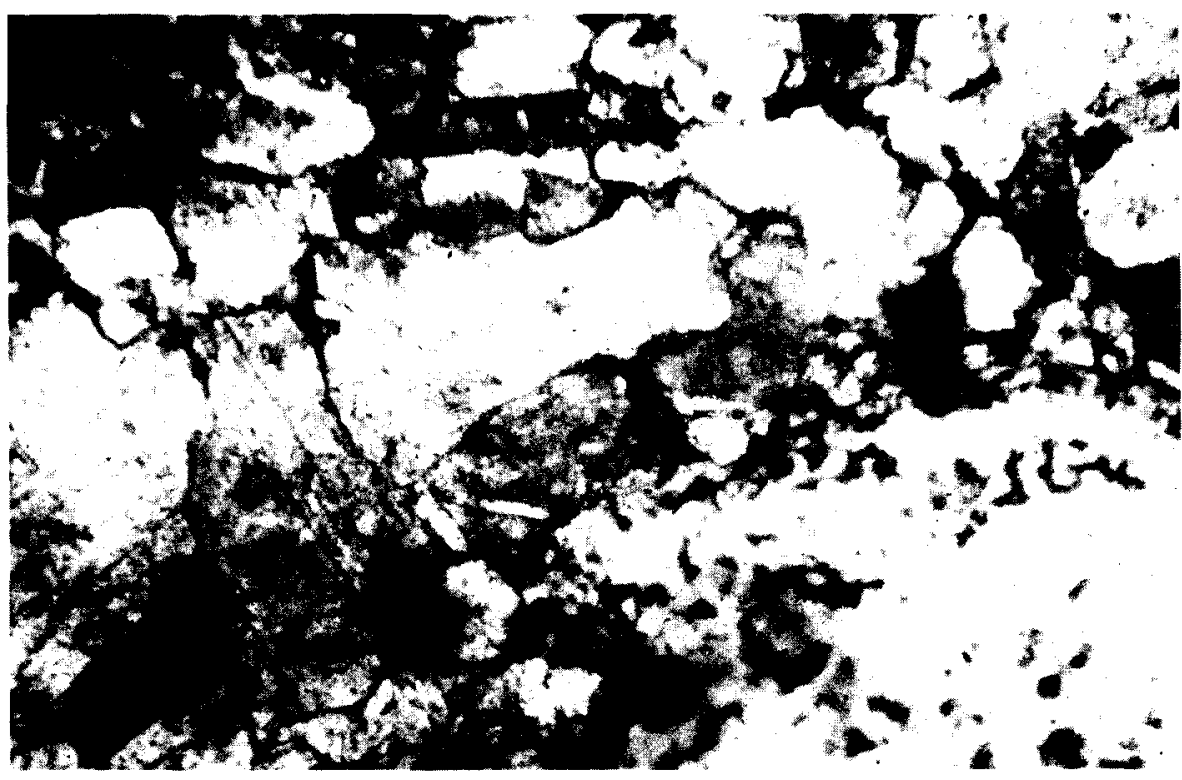

Fig. 5. Estructura metalográfica de un punzón de El Malagón (Granada). El pulido se ha efectuado sobre el talón de la pieza y revela una estructura de granos de sección poligonal, con bandas paralelas de deslizamiento (maclas) en el interior de alguno de ellos. Se trata de cobre arsenicado $(0,5 \%$ As) martilleado en frio y sometido a un tratamiento térmico de recristalización (recocido) que ha homogeneizado la composición del metal y generado granos poliédricos. El tamaño irregular de los granos indica que el recocido no es todavia perfecto. Las masas amorfas corresponden a productos de corrosión del cobre. Ataque con persulfato e hidróxido amónico. 280x.

bién más blanda. Ante ello, y siempre que el metalúrgico prehistórico fuera capaz de detectar los cambios acaecidos, el tratamiento de forja en frío posterior al recocido vendría a "compensar" la pérdida de dureza por recristalizado y oxidación de arsénico, pero nunca lograría la misma dureza previa al recocido debido a la merma de arsénico en la composición (para unas mismas condiciones de deformación del metal). En ello reside la contradicción.

Pero lo más probable es que los antiguos metalúrgicos nunca fueran conscientes de las cualidades del cobre arsenicado, y los procesos de taller tuvieran un significado (¿mágico?) ajeno a lo estrictamente metalúrgico. Los trabajos de varios investigadores, y en particular Budd (1992: 11-12), cuestionan muy razonadamente el supuesto "progreso" atribuido al cobre arsenicado, pues los estudios de laboratorio demuestran que los metalurgistas calcolíticos trabajaron el cobre ignorando en gran medi- 


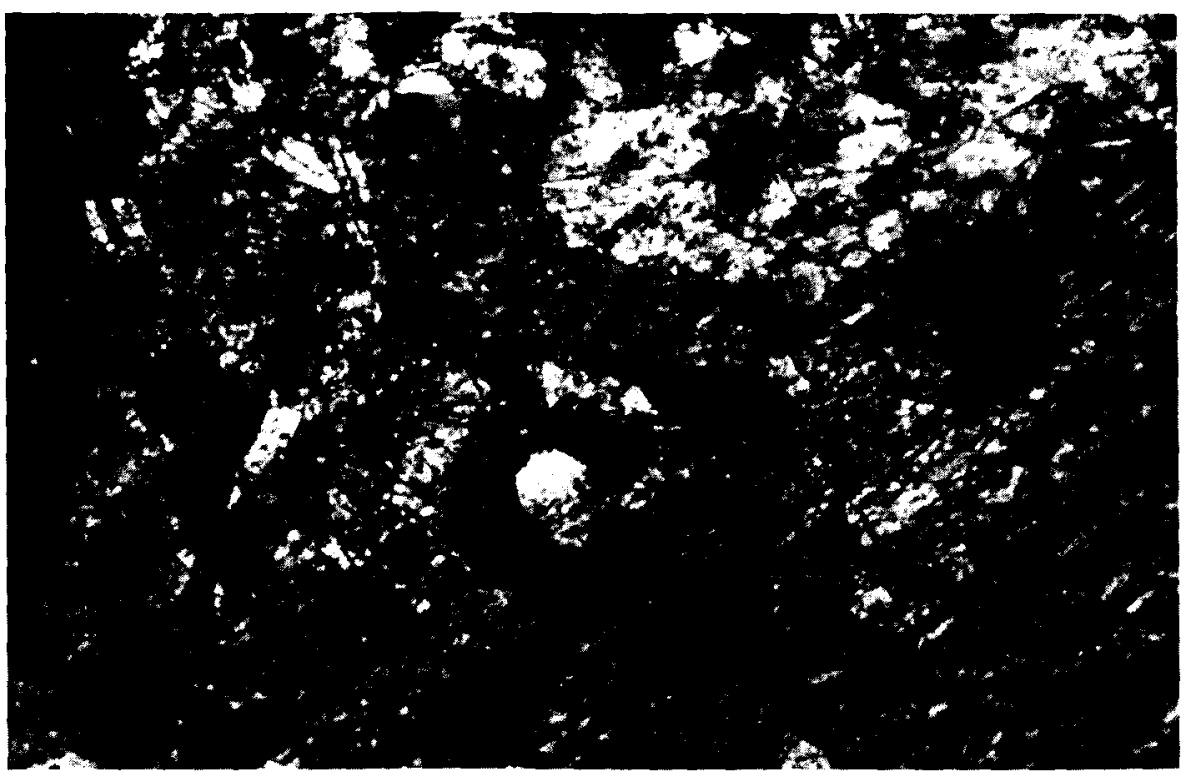

Fig. 6. Estructura metalográfica de un punzón del Dolmen de El Teriñuelo (Aldeavieja de Tormes, Salamanca). El pulido se ha efectuado sobre el talón de la pieza y revela una estructura de cobre arsenicado $(0,5 \%$ As) recocido y vuelto a martillear en frio. El último tratamiento de forja ha producido un ligero aplastamiento, pero, sobre todo, múltiples fracturas en los granos (lineas oscuras). Ataque con persulfato e hidróxido amónico. 160x.

da sus propiedades mecánicas, dado que no parece que las aprovecharan convenientemente. El trabajo empírico del metalario quedó confinado a ensayar procesos de taller cada vez más complejos que no mejoraban las cualidades mecánicas del producto. Con el empleo del bronce las cosas no fueron mejor, pues el bronce recocido también tiene menor resistencia a la rotura (dureza) que el forjado en frío, aunque es menos frágil. No obstante, no cabe duda que el bronce tiene mejores prestaciones que el cobre y en ellas reside su éxito como aleación.

Las varillas de metal de uso indeterminado comienzan a ser frecuentes en el Bronce Final, aunque será en el Hierro cuando se documenten más hallazgos. Ni sus aleaciones (figuras 7 y 8) ni los métodos de producción (figura 9) resultan significativamente diferentes de los observados en los punzones (habrian de tenerse en cuenta matices regionales difíciles de valorar ahora). La inversión de trabajo empleada en producirlos no deja de ser una incógnita sin una clara explicación.

En el caso de que se tratara de simples porciones de metal para refundir en pequeñas instalaciones domésticas y fabricar con ellas ọbje- 


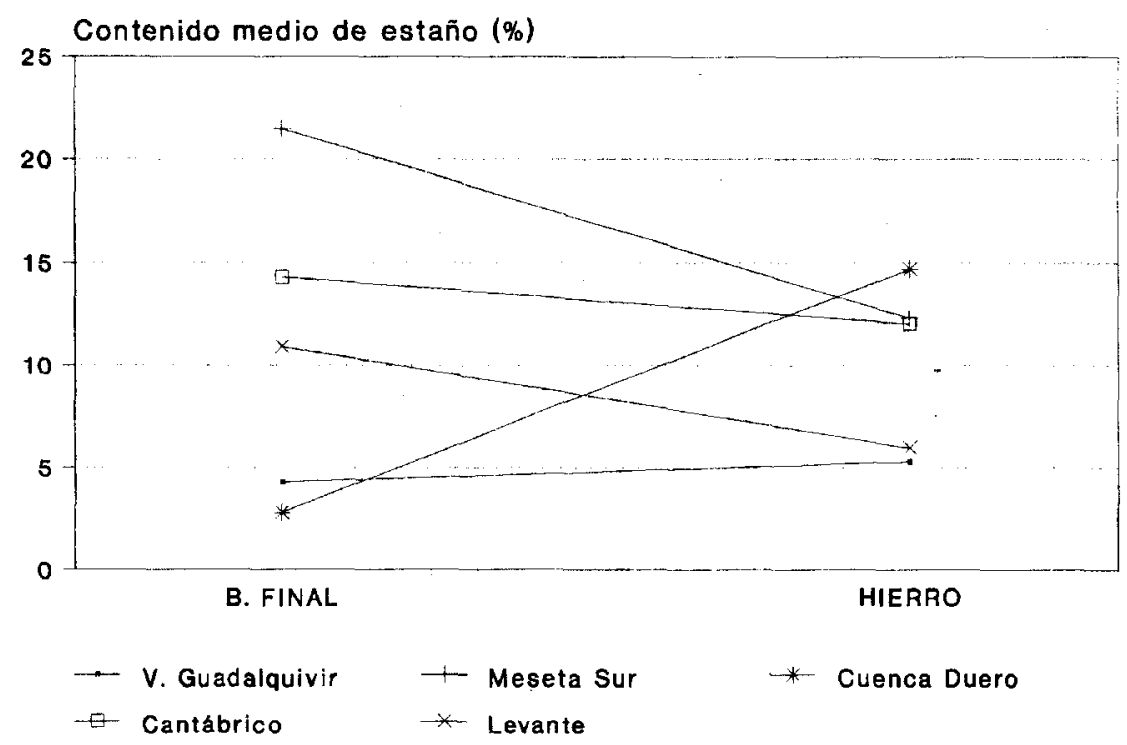

Fig. 7. Comportamiento del contenido medio de estaño en los punzones de bronce entre el Bronce Final y la Edad del Hierro. No se han tenido en cuenta los ejemplares de cobre.

tos de mayor peso (hipótesis que se ha barajado en más de una ocasión al denominarlas lingotillos), resultaría a todas luces innecesario aplicarles ningún tratamiento con posterioridad a sacarlas de la lingotera, puesto que ni el tamaño, ni la forma, ni el peso parecen obedecer a normas objetivables. Por otro lado, la ausencia de patrones cuantitativos en las aleaciones reflejadas en la figura 10 es acorde a la enorme diversidad de formulaciones empleadas en la metalisteria pre y protohistórica (RoviRA 1993), y no seria cortapisa para considerarlas materia prima con cierto grado de elaboración a la vista del panorama, aunque desde nuestro punto de vista el trabajo añadido estuviera de sobra.

Si se tratara de preformas para fabricar luego, por ejemplo, punzones, anillos, pulseras u otros pequeños útiles, el estado más adecuado del material sería como metal recocido, pues es en tal condición como mejor se podría trabajar. Este proceso ideal requeriría, a lo sumo, fundición+recocido. Sin embargo, las metalografías no apoyan esta hipótesis.

Otra posibilidad sería considerar las varillas como formas de acumulación de metal para un uso no estrictamente metalúrgico o incluso, como en el caso de los obeloi, como elemento de trueque en una economía 


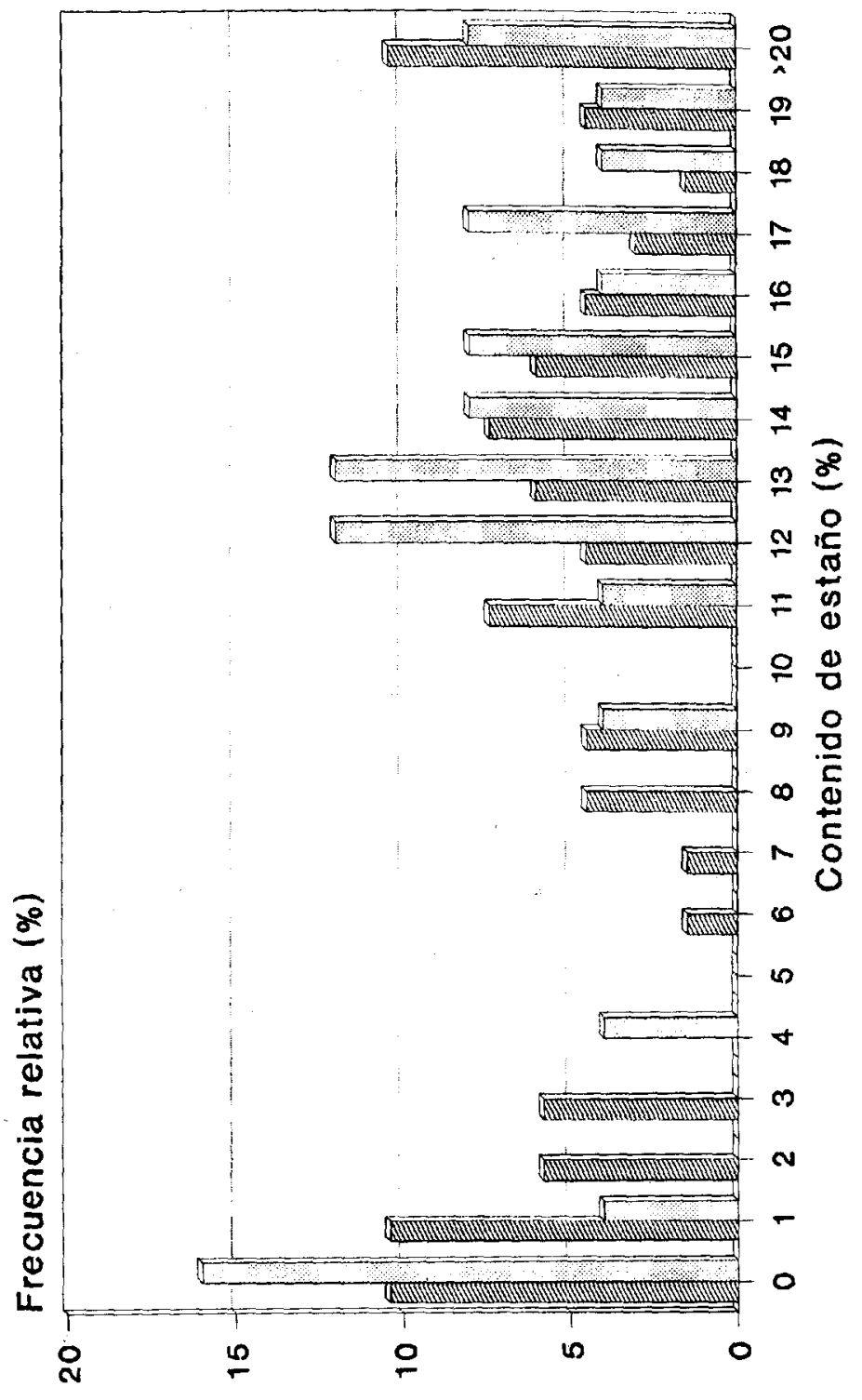

$\overline{8} \frac{1}{8}$

웅

岗

용

8

$8 \frac{8}{2}$

ธ

ป.

ธะ

y.

:

$\rightarrow 5$

\%

के

$\frac{\infty}{5}$

5

Q.

อิ

ธธ㇒

$\circ$ ह

'

ธ。

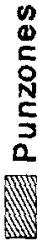

ฮ.

8

웡

응

Ф.

80

ब。

요

บ

50

跤

क

os

5

8 \%

क क

ํㅜㅇ

논

호

立表

$\infty$ o으

웡

倃全: 


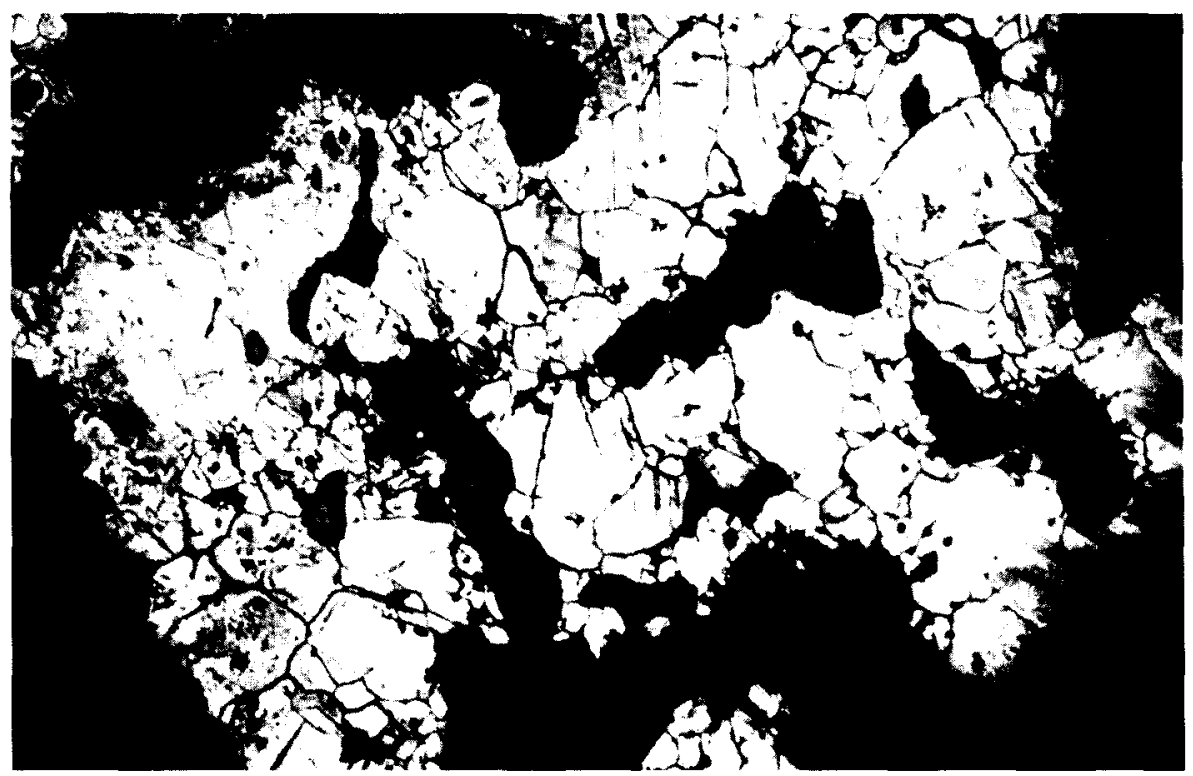

Fig. 9. Metalografia de una varilla de El Pic dels Corbs (Sagunto, Valencia). El pulido se ha efectuado sobre la sección de un extremo y muestra la estructura de un bronce $(13,9 \% \mathrm{Sn}$ ) martilleado en frio y recocido, con los característicos granos de sección poligonal. Las masas de tonalidad gris oscura corresponden a productos de corrosión que han invadido grietas y sopladuras de fundición. La estructura es similar a la del punzón calcolítico de El Malagón (fig. 5), aunque aquí se trata de una varilla del Bronce Final, con un tamaño de grano más pequeño y algo más uniforme. La ausencia de deformación del metal en frio indica que la pieza no se rompió ni fue cortada por esa parte, correspondiendo por tanto al extremo original de la varilla. Ataque con cloruro férrico $y$ ácido clorhidrico. 500x.

premonetal (Gómez Ramos, e.p.). Del descubrimiento de pesas, ponderales e incluso restos de auténticas balanzas (yugos y platillos) en yacimientos ibéricos (LuCAS 1990) se infiere un complejo mundo de relaciones protomonetales aún sin estudiar. Sin embargo, aquí tropezaremos con el escollo difícil de salvar de la inexistencia de patrón en las aleaciones. Así, por ejemplo, el coste de una aleación con 6 \% Sn debía ser distinto (ignoramos en qué grado y según qué regiones) al de otra con $12 \%$ Sn. Un metalúrgico avezado podría distinguir la diferencia por el color del metal limpio con una precisión, como mucho, de $\pm 3 \%$ sobre la tasa real de estaño y en ciertos márgenes de la composición, pero no sabemos si la gente común tenía tal habilidad, así como el valor en términos económicos de las imprecisiones cometidas. 


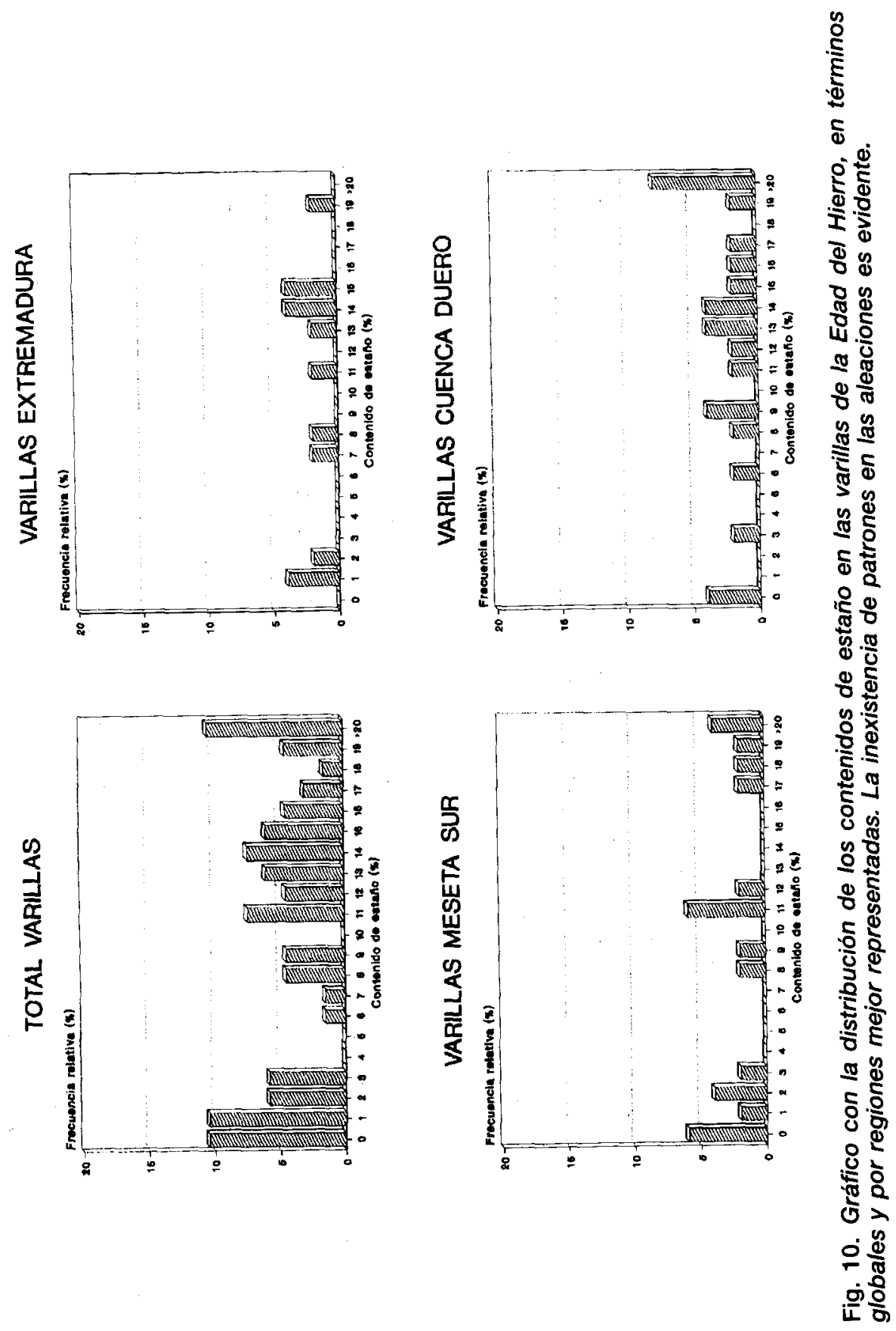


Todas estas dificultades invitan a pensar que el metal en bruto o en preformas sencillas, como objeto de transacción, debió circular por circuitos muy específicos y controlados por expertos si aceptamos que era una materia muy valiosa. Sin embargo, la profusión y características de los hallazgos obliga a matizar, sin prescindir de la consideración de materia valiosa, que probablemente el valor en el mercado de consumo se otorgaba al metal en sí y no a su composición química. Con este matiz se intentarían encajar una tecnología de taller con evidentes contradicciones, alimentada de urecetas" tradicionales poco justificadas, y una demanda consumidora cada vez más numerosa, dispuesta a adquirir objetos de metal de la más variada calidad.

\section{BIBLIOGRAFÍA}

Almagro Basch, Martín (1960): "Hallazgos arqueológicos de Villaverde", Memorias de Museos, Archivos y Bibliotecas, XVI-XVIII: 5-29.

Arribas, A.; Craddock, P.; Molina, B.; Rothenberg, y Hook, D.R. (1989): “Investigación arqueometalúrgica en yacimientos de las Edades del Cobre y del Bronce en el Sudeste de Iberia", en DOMERGUE, C. (coord.): Mineria y Metalurgia en las Antiguas Civilizaciones Mediterráneas y Europeas, 1: 71-79. Ministerio de Cultura, Madrid.

ARTEAGA, Oswaldo (1981): "Problemas de la Protohistoria de la Península Ibérica", Boletín de la Asociación Española de Amigos de la Arqueologia, 14: 4-16.

Blasco, C. y Rovira, S. (1992-93): "La metalurgia del cobre y del bronce en la región de Madrid", Tabona, VIII (II): 397-415.

Budo, Paul D. (1991): A Metallographic Investigation of Eneolithic Arsenical Copper. Department of Archaeological Sciences. Unv. of Bradford. Bradford.

- (1992): “Alloying and metalworking in the Copper Age of Central Europe», Bulletin of the Metals Museum (Japón), 17: 3-14.

CARO, Antonio (1988-89): “Los comienzos del II milenio a.C. en el Bajo Guadalquivir: EI tránsito del Cobre al Bronce", Zephyrus, XLI-XLII: 229-239.

- (1989): "Consideraciones sobre el Bronce Antiguo y Pleno en el Bajo Guadalquivir", en Tartessos: Arqueologia Protohistórica del Bajo Guadalquivir: 85-120. Barcelona.

Carrasco, J.; Pachón, J.A.; Malpesa, M., y Carrasco, E. (1980): Aproximación al Poblamiento Eneolítico en el Alto Guadalquivir. Museo de Jaén. Jaén.

Castaño, P.; Delibes, G.; Fernandez-Miranda, M.; Fernandez-Posse, M. ${ }^{a}$ D.; Mariscal, B.; Martín, C.; Montero, I., y Rovira, S. (1991): “Applications des méthodes archéométriques pour l'analyse du Chalcolitique du Bassin de Vera (Almería, Espagne), Revue d'Archéométrie, 15: 47-53.

ChARLES, J. A. (1980): "The coming of copper and copper-base alloys and iron: a metallurgical sequence", en T.A. WERTIME y J.D. MUHLY: The Coming of the Age of Iron: 151-181. Yale Unv. Press. New Haven \& London.

EiroA, Jorge J. (1980): La Cueva del Asno. Los Rábanos (Soria). E.A.E. 107. Madrid.

EscacenA, J.L. y Frutos, G. (1985): «El Monte Berrueco de Medina Sidonia (Cádiz): un modelo de transición del Calcolítico al Bronce en Andalucía Occidental", Gades, 13: 69-101.

Fernandez JURADO, Jesús (1988-89): “Aspectos de la minería y la metalurgia en la Protohistoria de Huelva", Huelva Arqueológica, X-XI (3): 177-214.

Fernandez-Posse, M.D. y MARTín, C. (1991): "El Calcolítico y la Edad del Bronce en la Meseta", Boletín de la Asociación Española de Amigos de la Arqueología, 30-31: 7586.

GIL-MASCARELL, Milagros (1981): “El Bronce Tardio y Bronce Final en el País Valenciano", en El Bronce Final y los Comienzos de la Edad del Hierro en el Pais Valenciano: 939. Monografias del Laboratorio de Arqueología de Valencia, 1. Valencia. 
Gómez Ramos, Pablo (e.p.): «Reflexiones sobre la identificación cincel/lingote y su posible valor premonetario durante el Bronce Final", Numisma.

GusI, F., y OlARIA, C. (1991): El Poblado Neoeneolítico de Terrera Ventura (Tabernas, Almeria). E.A.E. 160. Ministerio de Cultura. Madrid.

HARRISON, Richard J. (1974): "lreland and Spain in the Early Bronze Age", Journal of the Royal Society of Antiquearies of Ireland, 104: 52-73.

Hernandez Pérez, M.S., y López Mira, J.A. (1992): «Bronce Final en el medio Vinalopó. A propósito de dos conjuntos cerámicos del Tabaià (Aspe, Alicante)", en Estudios de Arqueologia Ibérica y Romana. Homenaje a Enrique Pla Ballester: 1-16. S.I.P., Serie de Trabajos Varios, 89 . Valencia.

JIMENO, A., y FERNÁNDEZ MORENO, J.J. (1992): «La metalurgia de la Edad del Bronce en la

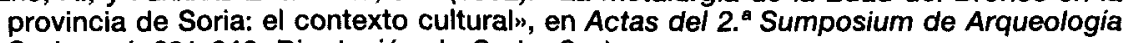
Soriana, 1: 231-246. Diputación de Soria. Soria.

KatincaRov, Roumen (1989): "Le développement des cultures Néolithique et Chalcolithique et l'apparition de la métallurgie sur les terres bulgares", en Le Premier Or de I'Humanité en Bulgarie. $5^{\mathrm{e}}$ Millénaire: 16-18. Réunion des Musées Nationaux. París.

LuCAS, Rosario (1990): "La balanza de dos platillos: el primer instrumento de medida conocido en la Península Ibérican, Verdolay, 2: 61-66.

LuLL, Vicente (1983): La "Cultura" de El Argar. Madrid. Akal.

MADDIN, R.; STECH, R., y MUHLY, J.D. (1991): "Çayönü Tepesy. The earliest archaeological metal artifacts", en MOHEN, J.P., Y ÉLUÉRE, CH. (coord.); Découverte du Métal: 375386. Picard. París.

martin, C.; Fernandez-Miranda, M.; Fernández-Posse, y Gillman, A. (1993): "The Bronze Age of La Mancha", Antiquity, 67: 23-45.

MARTín DE LA CRUZ, José C. (1991): “El Calcolítico y la Edad del Bronce en Andalucía", Boletin de la Asociación Española de Amigos de la Arqueologia, 30-31: 55-74.

MarTínez, C., y Botella, M. (1980): El Peñón de la Reina (Aldoloduy, Almeria). E.A.E.112. Ministerio de Cultura. Madrid.

MCKERRELL, H., y TYLECOTE, R.F. (1972): «The working of copper-arsenic alloy in the Early Bronze Age and the effect on the determination of provenance", Proceedings of the Prehistorical Society, 38 (1): 209-218.

MOLINA, Fernando (1978): “Definición y sistematización del Bronce Tardío y Final en el Sudeste de la Peninsula Ibérica», Cuadernos de Prehistoria de la Universidad de Granada, 3.

MONTERo, Ignacio (1992): Estudio Arqueometalúrgico en el Sudeste de la Península Ibérica. Col. Tesis Doctorales 91/92. Universidad Complutense. Madrid.

- (1992): «La actividad metalúrgica en la Edad del Bronce del Sudeste de la Península Ibérica: Tecnología e interpretación cultural", Trabajos de Prehistoria, 49: 189-215.

- (1993): "Bronze Age metallurgy in southeast Spain", Antiquity, 67: 46-57.

MONTERo, I.; RODRiguez, S., y RoJAS, J.M. (1990): Arqueometalurgia de la Provincia de Toledo. Minería y Recursos Minerales de Cobre. Diputación de Toledo. Toledo.

NeEdHAM, S.P.; LeESE, M.N.; HoOK, D.R., y HugheS, M. J. (1989): “Developments in the Early Bronze Age metallurgy of southern Britain", World Archaeology, 20 (3): 383-401.

Pellicer, Manuel (1986): “Cobre y Bronce Pleno en Andalucía Occidental”, en Homenaje a Luis Siret: $245-250$. Sevilla.

Peña, Antonio de la (1992): Castro de Torroso (Mos, Pontevedra). Xunta de Galicia. Coruña.

PrIEgo, C., y Quero, S. (1992): «El Ventorro, un poblado prehistórico de los albores de la metalurgia", Estudios de Prehistoria y Arqueologia Madrileñas, 8.

QUERO, Salvador (1982): "El poblado del Bronce Medio del Tejar del Sastre», Estudios de Prehistoria y Arqueologia Madrileñas, 1: 185-247.

RAPP, JR., George (1986): "The origins of copper and bronze alloying", en MADDIN, R., The Beginning of the Use of Metals and Alloys: 21-27. M.I.T. Press. Cambridge (Mass.) $\&$ London.

RoviRA, Salvador (1987): «Algunos aspectos de la tecnología metalúrgica en el Bronce Final y la Edad del Hierro", Bol. Asociación Española de Amigos de la Arqueología, 23: 53-57.

- (1989-90): “Estudio analítico de dos punzones de la Cova de Punta Farisa (Fraga)", Estudios de la Antigüedad, 6/7: 57-60. 
- (1993): "La metalurgia de la Edad del Hierro en la Peninsula Ibérica", en ARANA, R., et al., Metalurgia en la Peninsula lbérica durante el Primer Milenio a.C. Estado actual de la investigación: 45-70. Universidad de Murcia.

- (e.p.): "De metalurgia tartésica», en Tartessos, 25 años después. Jerez de la Frontera 1993.

ROVIRA, S.; CONSUEGRA, S., y MONTERo, I. (1987): «Estudio arqueometalúrgico de materiales de Tejada la Vieja", Huelva Arqueológica, IX: 221-234.

Rovira, S.; Consuegra, S., y MonTero, I. (1989): «Estudio arquometalúrgico de piezas metálicas de El Amarejom, en Broncano, S., El Depósito Votivo lbérico de El Amarejo. Bonete (Albacete): 101-104. E.A.E. 156. Madrid.

Rovira, S., y MONTERo, l. (e.p.): "Metales prehistóricos del entorno gaditano", en Aproximación a la Prehistoria de San Fernando. Ayuntamiento de San Fernando, Cádiz.

Rovira, S.; Montero, I., y Consuegra, S. (1992): “La metalurgia de la Edad del Bronce en la provincia de Soria: estudio analítico", en Actas del $2{ }^{\circ}$ Symposium de Arqueología Soriana, I: 247-259. Díputación de Soria. Soria.

Rovira, S., y SANZ, M." (1983): "Estudio arqueometalúrgico de las piezas metálicas de EI Peñón de la Reina (Alboloduy, Almeria)", Antropologia y Paleoecología Humana, 3: 193-214.

- (1984): "Análisis de laboratorio de algunos materiales de la Cueva de Juan Barbero", Trabajos de Prehistoria, 41: 94-104.

SchUBART, H., y ARTEAGA, O. (1986): «Fundamentos arqueológicos para el estudio socioeconómico y cultural del área de El Argar", en Homenaje a Luis Siret: 289-314. Sevilla.

Sesma, Jesús (1991): "Monte Aguilar: un poblado del Bronce Medio-Tardío en las Bárdenas Reales de Navarra", en Actas del XX Congreso Nacional de Arqueologia: 307-314. Zaragoza.

SIRET, Enrique y Luis (1890): Las primeras edades del metal en el Sudeste de España. Barcelona.

Soler, José Maria (1987): Excavaciones arqueológicas en el Cabezo Redondo (Villena, Alicante). Instituto de Estudios «Juan Gil-Albert» y Diputación Provincial de Alicante. Alicante.

Ulreich, H.; Negrete, M.A., y Puch, E. (1993): «Verzierte Keramik von Hoyas del Castillo, Pajaroncillo (Cuenca)", Madrider Mitteilungen, 34.

VALDÉS, Luis (1989): "Los primeros objetos de cobre del País Vasco. Consideraciones a la introducción de la metalurgia", Kobie (Serie Paleoantropologia), XVIII: 65-86.

VALIENTE, Jesús (1993): «Metalurgia en el poblado de La Loma del Lomo (Guadalajara, España)m, Actas dos Trabalhos de Antropologia e Etnologia, Vol. XXXIII, Fasc. 3-4: 301-317. 